\title{
Platform Competition and Access Regulation on the Internet
}

\author{
Sue H. Mialon and Samiran Banerjee*
}

May 15, 2012

\begin{abstract}
We provide a new model of platform competition on the Internet to analyze the effect of Net Neutrality regulation on market outcomes. Consumers subscribe to two vertically related platforms, an Internet service provider (ISP) and a content network platform (CNP), to reach content providers (CPs). CPs interact with consumers via CNPs. Local ISPs provide an essential input: the Internet connection for consumers and the last-mile access for the CNPs. Access regulation that lowers the ISPs' last-mile access charges may not increase consumer Internet prices, implying that the "seesaw principle" between consumer Internet prices and access charges may not hold in some cases. The effect on consumer Internet prices depends on how responsive CNPs' advertising fees are to changes in the Internet prices and access charges. If CNPs' fees are highly responsive to the changes, access regulation lowers both the fees from CPs and consumer Internet prices. On the other hand, if CNPs' fees are not so responsive, access regulation induces higher consumer Internet prices. The overall welfare implication of access regulation depends on its impact on consumer demand for the Internet. If access regulation generates greater consumer demand for the Internet, it improves total welfare. However, if it reduces consumer demand substantially, CPs are also worse off, and welfare decreases.

Keywords: Internet, Net Neutrality, Open Access Regulation, Two-Sided Markets.

JEL codes: L51, L86, L13, D43
\end{abstract}

*Sue Mialon (corresponding author, E-mail: smialon@emory.edu), Department of Economics, Emory University, Atlanta, GA 30322-2240. Samiran Banerjee, Department of Economics, Emory University, Atlanta, GA 30322-2240. We are very grateful to Byung-Cheol Kim, Preston McAfee, Maxwell Stinchcombe, Xuejuan Su, Kathy Zeiler, and seminar participants at Georgetown Law School for helpful comments. 


\section{Introduction}

Net neutrality, which requires all data packets to be treated equally regardless of their type or destination, is often considered to be the key factor responsible for the rapid growth of the commercial Internet since its inception. Meanwhile, as technological advancement made it possible to deliver new digital products such as VoD, VoIP, and IPTV via the Internet, there has been an increasing demand for larger and faster bandwidth capacity to support them. Internet Service Providers (ISPs) argue that net neutrality stifles their incentive to invest in the physical network because high bandwidth users "free-ride" on their infrastructure, making it impossible to provide the desired quality of service without additional revenue. ${ }^{1}$

In December 2010, in an attempt to preserve the nature of open and equal access, the FCC proposed a set of net neutrality rules prohibiting ISPs from blocking traffic on the Internet and from "unreasonably" discriminating against traffic. In April 2011, the House of Representatives voted to repeal the net neutrality rules, but in November 2011 the Senate voted to uphold them and the new rules went in effect. However, the FCC still faces challenges in upholding the net neutrality rules in court (see Verizon vs. FCC, for example), especially after the US Appeals Court in 2008 ruled that the FCC did not have the authority to order Comcast to stop throttling file-sharing traffic.

Our paper examines the impact of net neutrality and its revocation in the context of open access regulation of the Internet. We introduce a two-tiered platform competition model in which two types of vertically related platforms, ISPs and content network platforms (CNPs) such as Google or Amazon, mediate the consumers and content providers (CPs). There are two horizontally differentiated ISPs and two homogenous CNPs. Consumers need an Internet connection from either of the ISPs and at least one of the CNPs to reach CPs. CPs use CNPs' distribution channels to reach consumers. In our framework, consumers choose to single-home, using one CNP to find CPs, while CPs multi-home and use both CNPs. Such a market configuration results in "competitive bottlenecks" because "platforms have monopoly power over providing access to their single-homing customers for the multi-homing side" (Armstrong, 2006, pp.669).

\footnotetext{
${ }^{1}$ There have been several incidents where ISPs have refused to transmit a particular traffic, igniting a debate around net neutrality. For example, in 2004, Vonage filed a complaint against Madison River Communications to the U.S. Federal Communications Commission (FCC) alleging that Madison River blocked VoIP calls of Vonage customers (E-Commerce Times, March 4, 2005, "FCC Fines Telecom that Blocked Vonage VOIP Calls"). In 2007, the Associated Press reported that Comcast slowed down BitTorrent's peer-to-peer traffic in the name of network management (Associated Press, October 19, 2007, "Comcast Blocks Some Internet Traffic"). In 2010, Level 3 Communications, a major partner of Netflix, accused Comcast of charging fees which put Internet video companies at a significant disadvantage (The Economist, December 23, 2010, "Peer Pressure"). See section 6.2 for the discussion of net neutrality regulation in the cable TV industry and VOIP services.
} 
Modeling CNPs as the platforms of the two-sided market between consumers and CPs differentiates our paper from existing models where ISPs are the intermediaries between consumers and CPs. In those models, consumers (CPs) derive a greater network externality from joining an ISP if a greater number of CPs (consumers) participate in that ISP's network. In contrast, consumers and CPs derive network externality from the CNPs' network in our paper.

It is more realistic to model consumers and CPs as deriving network externalities from the CNPs' network and not from the ISPs' network for several reasons. First, consumers and CPs often do not use the same ISP network. Second, most products advertised on the Internet are normally provided via platforms, not individually (for example, online flower shops on Google or books on Amazon). Finally, since it is the CNPs that need the last-mile access to consumers, if net neutrality is revoked, the immediate impact of paid prioritization or any other discrimination mechanism is likely to fall on the CNPs, instead of on the individual CPs. ISPs often accuse "a very small fraction of the users" (the CNPs) of using most of the bandwidth. Significantly, all of the recent net neutrality cases involve disputes between ISPs and CNPs.

When CNPs mediate consumers and CPs, the role of local ISPs is to provide an essential input - the Internet connection - so that consumers are able to make purchases online and CNPs can use the last-mile access to deliver the products and complete the transactions. CNPs normally pay a one-time fee to a transit ISP. This gives them access to the consumers connected to local ISPs which in turn are connected to transit ISPs or other local ISPs under peering arrangements. ${ }^{2}$ The net neutrality controversy is founded on the question of whether or not the CNPs should also pay for the last-mile access provided by the local ISPs. Currently, net neutrality rules prohibit local ISPs from "unreasonable" discrimination of CNPs for access to consumers. Paid prioritization is unlikely to satisfy the "no unreasonable discrimination" rule. ${ }^{3}$ While there are many aspects of the net neutrality rules, we take the revocation of net neutrality to mean that local ISPs can charge CNPs for last-mile access to consumers. Figure 1 illustrates the structure of the Internet and the impact of abolishing net neutrality in our model.

We find that the effects of access regulation that lowers access charges below the unregulated market equilibrium level depend on how CNPs respond to ISPs' price changes. In contrast to existing models, we find that lowering access charges may lower the Internet price for consumers. This happens when CNPs' fees change a lot in response to ISPs' price changes. Higher access charges inflate CNPs' fees as the cost of operation for CNPs increase. On the other hand, when Internet prices are higher,

\footnotetext{
${ }^{2}$ Peering is a restricted service whereby two interconnecting networks agree not to pay each other for carrying the traffic exchanged between them as long as the traffic originates and terminates in the two networks.

${ }^{3}$ See The Federal Register Volume 76, Number 185 (Friday, September 23, 2011) http://www.gpo.gov/fdsys/pkg/FR-2011-09-23/html/2011-24259.htm
} 


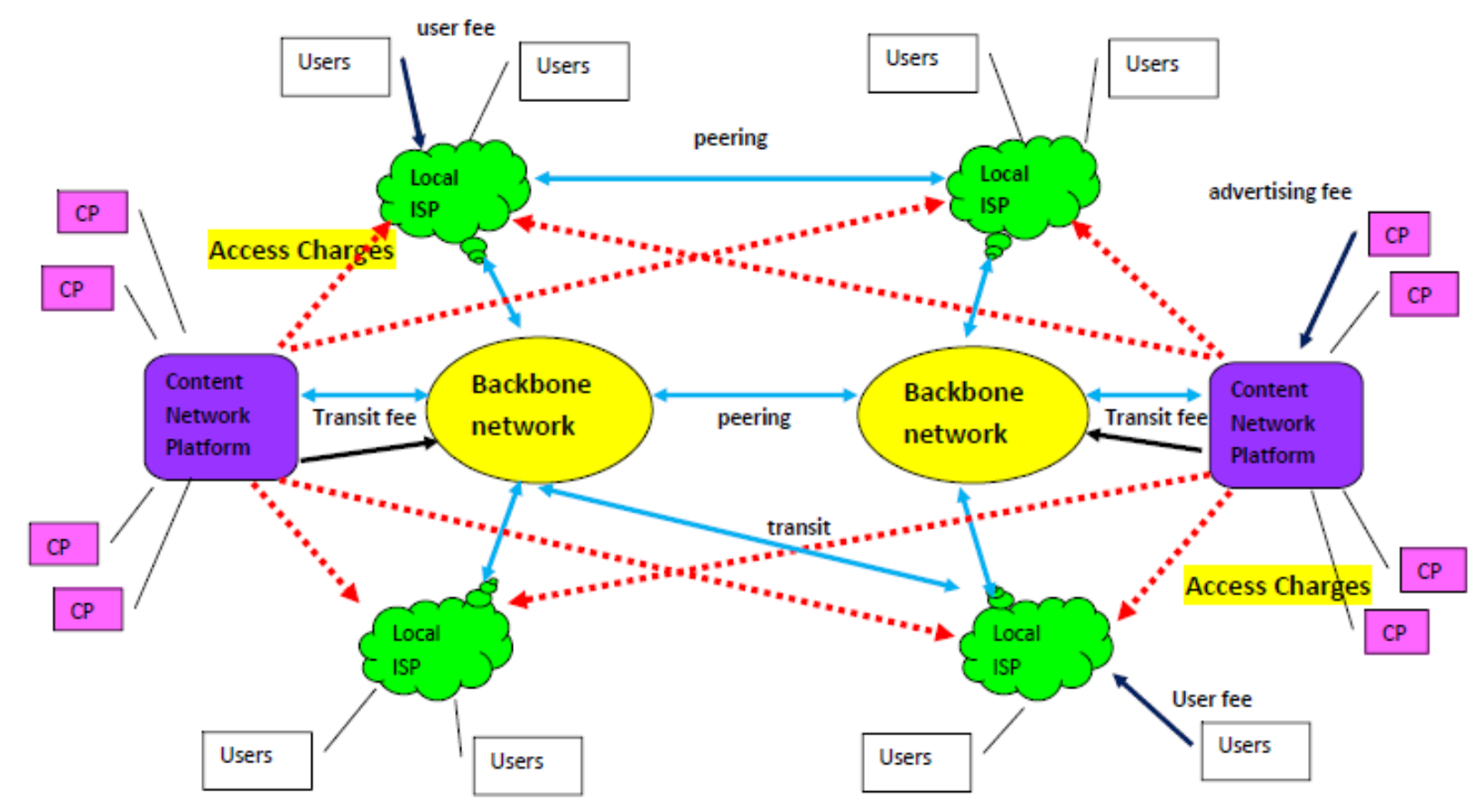

Figure 1: Internet Traffic and Non-Net Neutrality.

CNPs optimally lower their advertising fees to minimize the impact on transaction volume, which gives ISPs an incentive to set higher Internet prices. When this effect is significant, access regulation results in lower Internet prices. The effect is significant if CPs' participation is highly elastic to the changes in access charges and consumer Internet prices than is consumer demand for the Internet. Since consumer demand for the Internet is relatively less elastic, ISPs use higher Internet prices mainly to increase access revenues since higher Internet prices would lower CNPs' fees and thus induce greater participation of CPs. In this situation, if access regulation takes place, it limits the access revenue ISPs can make via higher Internet prices, and thus, ISPs lower their Internet prices.

Typically, it is predicted that the prices of the two sides of the market are inversely linked: a factor that raises the price on one side tends to lower the price on the other side (the "seesaw principle"). This paper shows that the "seesaw principle" may break down depending on CNPs' fee pricing. Other models that do not account for the role of CNPs predict that the consumer Internet price would increase as a result of net neutrality regulation. We show that depending on CNPs' responses, the consumer Internet price could be lower. Our framework thus offers a new insight regarding platform competition on the Internet and the role of access charges.

Price alone, however, is not a good gauge of the welfare implications of policy in 
two-sided markets where network externality is an important consideration for the participants. Even if consumer prices increase, consumer demand can increase due to enhanced network externalities. Network participation increases if and only if the participants receive a greater surplus. For this reason, we find that if access regulation induces greater participation from consumers as well as from CPs, it unambiguously improves welfare. Thus, the levels of consumer demand for the Internet and CPs' network participation can be better indicators of the welfare consequences of access regulation.

What is at the heart of the debate about net neutrality is that the market for the Internet is currently far from being fully covered. Proponents of net neutrality often refer to "Internet for everyone" as the main reason to uphold net neutrality, under the premise that a lower access charge plays a key role in keeping the market demand up, and even in expanding the coverage of the Internet. This argument implicitly assumes that (i) a lower access charge is effective in inducing a greater demand from consumers, and (ii) an increase in consumer demand for the Internet is crucial in enhancing welfare. There is no reason a priori why the two conditions must hold. However, we find that while a low access charge does not necessarily induce greater demand from consumers, if it does, it does improve overall welfare.

Although it is commonly expected that access regulation will positively impact the CPs, the effect is ambiguous depending on what happens to consumer demand. If regulation lowers consumer demand for the Internet and thus reduces transaction volume substantially, CPs can be worse off as a result of access regulation even though they pay lower fees for advertising.

Hence, the overall effectiveness of access regulation crucially depends on how it affects consumer demand. Our model predicts that access regulation is very effective if the impact on consumer demand is positive. If consumer demand for the Internet is more responsive than CPs' participation to the changes in Internet prices and network externalities, access regulation may reduce welfare. Thus, the efficiency of access regulation on the Internet would require empirical evidence indicating that consumer demand for the Internet is relatively stable and inelastic and that CPs have much larger potential for growth given the inefficiency of monopoly market power of ISPs and CNPs. Without sufficient information on both sides of the market, it is difficult to ensure that "one-sided" regulation results in welfare improvement on both sides. Thus, a great deal of caution should be exercised in implementing a "one-sided" regulation in two-sided markets.

Once access regulation on the Internet is viewed as the pricing of a crucial monopoly input provided by ISPs, there are parallels between access regulation on the Internet and traditional (one-way) access-pricing in telecommunications. While the provision of local phone services exhibits a natural monopoly, other stages of production such as long-distance call services can be open to competition so long as potential entrants are able to use the crucial input-access - provided by the monopoly incumbent. 
Typically there is no private incentive for the incumbent to provide access at a fair price, and thus, access price regulation is necessary to promote competition.

The question is whether the same logic applies to the Internet. The new net neutrality proposal declares the FCC's legal authority to manage ISPs under Title II and Section 706 of the Telecommunications Act. However, in 2005, the FCC classified Internet transmissions as "information services" instead of "telecommunication services". For this reason, in 2008, the court found in Comcast vs. FCC that the FCC did not have the authority to regulate Internet transmissions. Hence, whether there is any common ground between the role of access charges in telecommunications and that of access charges in the Internet marketplace is an important issue in determining the FCC's jurisdiction over Internet regulation.

There are a couple of differences in the case of the Internet. First, local ISPs are normally not in direct competition with CNPs. ${ }^{4}$ Second, since ISPs mainly serve a regional network area, they are unable to replace CNPs' national network services and thus unable to foreclose CNPs. CNPs normally have a great deal of market power. Since the CNPs' market power normally comes from network externalities, any potential entrant is required to have a commensurate level of established network, which constitutes a significant entry barrier even to ISPs covering many regions. When foreclosure is not possible, ISPs may not have an incentive to charge an exorbitant price for access. Our model predicts that if the profitability of the CPs is thin and consumer demand for Internet is low, the ISPs may charge a zero access fee voluntarily in order to enhance the network participation of the two sides.

Compared to typical two-sided markets with only one layer of platforms, access regulation is more likely to be effective on the Internet because the immediate beneficiaries, CNPs, are the platforms of the market and they do not benefit from higher consumer prices. For the reason that CNPs have market power, access regulation may look less ideal on the surface since the immediate effect of the regulation is to lower the operating costs for the CNPs. However, this paper shows that because CNPs consider consumer prices in deciding their advertising fees, access regulation can result in a lower price for consumers. Since lower Internet prices induce a greater demand from consumers and higher welfare, there is a greater likelihood that access regulation will improve welfare on the Internet than it would in typical two-sided markets.

The rest of the paper is organized as follows. Section 2 briefly reviews related literature. Section 3 presents our basic two-sided market framework where CNPs intermediate CPs and consumers, while the ISPs provide an essential input to CNPs and consumers. Section 4 summarizes the symmetric equilibrium. Section 5 analyzes the effect of access regulation. Section 6 discusses the role of CNPs, the implication

\footnotetext{
${ }^{4}$ While most of the internet business models fit into our framework in which the ISPs and CNPs are not in direct competition, online movies and IPTV markets are exceptions. See section 6.2 for a brief discussion about these cases.
} 
of open access regulation, and the difference in access-pricing in Internet markets. Section 7 concludes.

\section{Literature Review}

The theoretical literature on access regulation and net neutrality in two-sided market framework is quite sparse. ${ }^{5}$ Schuett (2010) provides a timely survey of the existing literature related to net neutrality issues. While there is no single definition of net neutrality, the most common interpretation refers to a "zero-price rule," the situation when last-mile access charges are zero. Lee and Wu (2009) provide a detailed discussion of the issues from this perspective. Economides and Tåg (2012) examine the effect of net neutrality regulation in a monopoly as well as in a duopoly ISP setting. In the case of a monopoly ISP, they find that without net neutrality, the price consumers pay for Internet access decreases, but consumers have access to less content, so the impact on total surplus is ambiguous. However, in a duopoly setting, the absence of net neutrality decreases the total surplus because positive access fees reduce the mass of active content providers. Musacchio et al. (2009) model how zero access pricing under net neutrality regulation affects platforms' investment incentives in a two-sided market framework. They show that neutrality is desirable if the ratio of advertising revenue per click to the price elasticity of demand for Internet subscriptions is moderate. In their model, each ISP's access charge imposes a negative externality on other ISPs by decreasing the content and lowering consumers' willingness to pay. Not recognizing this externality, ISPs are likely to overcharge when they are allowed to charge for access. Thus, neutrality can increase welfare in this case.

The remaining literature looks at net neutrality from the point of non-discrimination, preventing ISPs from prioritizing traffic by setting differing prices for differing qualities of service or by unilaterally deciding whether to degrade the traffic of content providers. Hermalin and Katz (2007) show that the overall effect of such productline restrictions in the context of a monopoly ISP is ambiguous. Choi and Kim (2010), Cheng et al. (2010), Krämer and Wiewiorra (2010), and Economides and Hermalin (2012) explicitly model network congestion to look at the welfare effects of quality/price discrimination by a monopoly ISP. In particular, Choi and Kim (2010) investigate the impact of paid prioritization on the investment incentives of ISP and CPs. In the framework of a monopolist ISP and duopoly content providers, they find that paid prioritization has two opposite effects on the R\&D incentives: a positive effect from the increased network access fees and a negative effect from lower rent extraction. If the reduction in rent extraction is dominant, paid prioritization may in fact reduce the ISP's incentive to invest in the network. Economides and Hermalin

\footnotetext{
${ }^{5}$ Independently of the issues regarding net neutrality, there has been a growing literature on the economics of two-sided markets. See Caillaud and Jullien (2003), Rochet and Tirole (2003, 2006), and Armstrong (2006), for example.
} 
(2012) find that the ability to price-discriminate increases ISP's incentives to invest in infrastructure. However, they point out that time sensitive contents are not necessarily elastic with respect to transmission time. Thus, if the contents are inelastic, they find that price discrimination based on differential transmission time lowers welfare and thus welfare is higher under net neutrality than under any implementable price discrimination.

The novelty of our paper lies in the new platform competition model in which the relationship between two vertical platforms plays a key role in determining the welfare effects of access regulation. To our knowledge, this is the first vertical platform competition model that analyzes the effects of access regulation. This framework also provides a new insight on the "seesaw principle" between the prices of the two-sided markets and when it can break down.

As the majority of the existing literature primarily focuses on the effect of access regulation on ISPs' incentives to invest in infrastructure, there has been lack of progress in understanding how access regulation can achieve its primary goal of inducing greater consumer demand and whether an increase in demand implies higher welfare. Our analysis focuses on the effect on consumer demand for the Internet to better understand the effectiveness of access regulation. We find that the impact on consumer demand is a key factor to the welfare implication of access regulation and that access regulation does effectively induce greater demand for the Internet in some parameter ranges, thereby contributing to a higher welfare.

\section{The Model}

The main actors of the model are two Internet service providers (ISPs), two content network platforms (CNPs), a unit mass of content providers (CPs or sellers), and a unit mass of consumers (buyers or end-users). The timing of interactions among buyers, CPs, CNPs and ISPs are as follows. In stage 1, ISPs move simultaneously to set the Internet connection prices for consumers and last-mile access charges for CNPs. In stage 2, CNPs set their fees for CPs. Finally, in stage 3, CPs and consumers simultaneously decide whether to participate in the CNPs. The next four subsections looks at the decision-making problems of consumers, CPs, CNPs and ISPs in turn.

\subsection{Consumers}

Each consumer purchases at most one Internet connection. Each consumer has a preference for ISP $i$ captured by a preference parameter $\theta_{i} \in[0,1]$, which shows the individual value of the Internet connection provided by ISP $i=1,2$. These parameters are assumed to be uniformly and independently distributed over the unit intervals. When a consumer single-homes with a CNP $j, j=1,2$, we can write the 
utility for a consumer as

$$
u_{i j}=\theta_{i}+\nu+\lambda E\left(N_{j}^{s}\right)-p_{i}-c
$$

where $\nu$ is the value of network services jointly provided by ISPs and CNPs, $\lambda E\left(N_{j}^{s}\right)$ the consumer's valuation of the expected network externality when the consumer expects that CNP $j$ features $N_{j}^{s}$ content providers, $p_{i}$ the price charged by ISP $i$ from buyers for Internet access, and $c$ the personal cost of setting up an account at one CNP and learning the platform environment. We assume that $c$ is symmetric across CNPs. Hence, to consumers, CNPs differ only in the extent of their network externality, implying that when they single-home for CNPs, they prefer one with a larger network.

On the other hand, if a consumer multi-homes, the utility for the consumer is

$$
u_{i 12}=\theta_{i}+\nu+\lambda E\left(\bar{N}^{s}\right)-p_{i}-c_{12}
$$

where $\bar{N}^{s}$ is the total number of participating CPs and $c_{12}$ is the cost of setting up accounts in both platforms. We assume that $c_{12}>c$. Consumers decide to singlehome CNP $j$ if and only if $u_{i j}>u_{i 12}$, i.e.,

$$
c_{12}-c>\lambda E\left(\bar{N}^{s}-N_{j}^{s}\right) .
$$

As the condition does not depend on each consumer's individual valuation of the Internet, all consumers either single-home or multi-home. In other words, it is never the case that some consumers single-home while others multi-home. If $E\left(\bar{N}^{s}\right)=$ $E\left(N_{1}^{s}\right)=E\left(N_{2}^{s}\right), c_{12}-c>0$, the condition is always satisfied, and thus, all consumers single-home. In Appendix A, we show that consumers single-home in equilibrium.

Let $D_{i j}^{e}$ denote the expected demand for those who use ISP $i$ and $\operatorname{CNP} j(i, j=$ $1,2)$ when consumers single-home for a CNP. A consumer belongs to $D_{i j}^{e}$ if and only if her utility satisfies $u_{i j} \geq 0, u_{i j} \geq u_{i^{\prime} j}, u_{i j} \geq u_{i j^{\prime}}$, and $u_{i j} \geq u_{i^{\prime} j^{\prime}}$, where $i^{\prime}, j^{\prime}=1,2$, $i^{\prime} \neq i$ and $j^{\prime} \neq j$. For example, for consumers who use ISP 1 and CNP 1, it must be that $u_{11} \geq u_{12}, u_{11} \geq u_{21}$, and $u_{11} \geq u_{22}$. The condition $u_{11} \geq u_{12}$ (and likewise, $\left.u_{21} \geq u_{22}\right)$ implies that $D_{11}^{e}>0\left(D_{21}^{e}>0\right)$ if and only if

$$
E\left(N_{1}^{s}\right) \geq E\left(N_{2}^{s}\right)
$$

If the inequality is strict, consumers join the larger network $\left(N_{1}^{s}\right)$ while $D_{12}^{e}=0$ $\left(D_{22}^{e}=0\right)$; otherwise, consumers split the demand.

From $u_{11} \geq u_{21}$ (and likewise, from $u_{12} \geq u_{22}$ ), we obtain

$$
\theta_{2} \leq \theta_{1}+p_{2}-p_{1}
$$


The condition $u_{11} \geq u_{22}$ gives $\theta_{2} \leq \theta_{1}+p_{2}-p_{1}+\lambda\left(E N_{1}^{s}-E N_{2}^{s}\right)$, which is always satisfied as long as (4) and (5) are satisfied. Moreover, from $u_{i j} \geq 0(i, j=1,2)$, we obtain the following individual rationality constraints:

$$
\begin{aligned}
& \theta_{1} \geq p_{1}-x \equiv \hat{\theta}_{1}, \\
& \theta_{2} \geq p_{2}-x \equiv \hat{\theta}_{2},
\end{aligned}
$$

where $x=\nu-c+\lambda N^{s}$ is the net utility from network service and $N^{s}=\max \left\{E\left(N_{1}^{s}\right), E\left(N_{2}^{s}\right)\right\}$. Similarly, we can define the conditions when $u_{21} \geq u_{11}$ and when $u_{22} \geq u_{12}$. Thus inequalities (5)-(7) and their converse characterize the demands $D_{i j}$.

1. If $E\left(N_{1}^{s}\right)=E\left(N_{2}^{s}\right)=N^{s}$, of all the consumers who subscribe to ISP $i$, half use CNP 1 and the other half use CNP 2. Then

$$
\begin{aligned}
D_{11} & =\frac{1}{2}\left[\left(1-\hat{\theta}_{1}\right) \hat{\theta}_{2}+\frac{\left(1-\hat{\theta}_{1}\right)\left(1+p_{2}-p_{1}-\hat{\theta}_{2}\right)}{2}\right] \\
& =\frac{1}{2}\left[\hat{\theta}_{2}\left(1-\hat{\theta}_{1}\right)+\frac{1}{2}\left(1-\hat{\theta}_{1}\right)^{2}\right]=D_{12} .
\end{aligned}
$$

Similarly,

$$
D_{21}=\frac{1}{2}\left[\left(1-\hat{\theta}_{2}\right)-\frac{1}{2}\left(1-\hat{\theta}_{1}\right)^{2}\right]=D_{22} .
$$

Let $N_{j}^{b}$ be the number of buyers who use CNP $j$. Since $N_{1}^{b}=D_{11}+D_{21}$, and $N_{2}^{b}=D_{12}+D_{22}$, given that $D_{11}=D_{12}$ and $D_{21}=D_{22}$, we get

$$
N_{1}^{b}=N_{2}^{b}=N^{b}=\frac{1}{2}\left(1-\hat{\theta}_{1} \hat{\theta}_{2}\right) .
$$

2. If $E\left(N_{1}^{s}\right)>E\left(N_{2}^{s}\right)$, any consumers who purchase an ISP connection single-home with CNP 1 , resulting in $D_{11}^{M}=\hat{\theta}_{2}\left(1-\hat{\theta}_{1}\right)+\frac{1}{2}\left(1-\hat{\theta}_{1}\right)^{2}, D_{21}^{M}=\left(1-\hat{\theta}_{2}\right)-\frac{1}{2}\left(1-\hat{\theta}_{1}\right)^{2}$, $D_{12}=D_{22}=0, N_{1}^{b}=1-\hat{\theta}_{1} \hat{\theta}_{2}, N_{2}^{b}=0$, and vice versa for the case of $E\left(N_{1}^{s}\right)<$ $E\left(N_{2}^{s}\right)$.

\subsection{Content Providers}

Each CP is characterized by an index of profitability $\phi$ which is uniformly and independently distributed over $[0, \bar{\phi}]$. CPs pay $f_{j}$ to CNP $j(j=1,2)$ per click/purchase that consumers make online. We assume that the clicks or units purchased have a one-to-one relationship with the size of consumers in the network. When consumers single-home, for a given $f_{j}$, CP $k$ 's profit function from joining $\mathrm{CNP} j$ is given by

$$
\pi_{k}^{C P}=\left(\phi_{k}-f_{j}\right) E\left(N_{j}^{b}\right) .
$$


Thus, CP $k$ joins CNP $j$ if and only if $\phi_{k} \geq f_{j}, j=1,2$, for otherwise it makes a loss. Then, CP $k$ 's overall profit function from multi-homing is

$$
\pi_{k}^{C P}=\max \left\{\left(\phi_{k}-f_{1}\right) E\left(N_{1}^{b}\right), 0\right\}+\max \left\{\left(\phi_{k}-f_{2}\right) E\left(N_{2}^{b}\right), 0\right\},
$$

while the profit from single-homing with CNP $j$ is $\pi_{k}^{C P}=\max \left\{\left(\phi_{k}-f_{j}\right) E\left(N_{j}^{b}\right), 0\right\}$. If $f_{1}=f_{2}=f$, all content providers with $\phi \geq f$ multi-home. This implies that given the uniform distribution of CPs over $[0, \bar{\phi}]$,

$$
N_{1}^{s}=N_{2}^{s}=N^{s}=1-\frac{f}{\bar{\phi}} .
$$

If $f_{1}>f_{2}$, however, the CPs with $\phi \in\left[f_{1}, \bar{\phi}\right]$ multi-home, while those with $\phi \in\left[f_{2}, f_{1}\right]$ choose single-homing provided that $E\left(N_{1}^{b}\right)>0$, resulting in

$$
N_{2}^{s}=1-f_{2} / \bar{\phi}>N_{1}^{s}=1-f_{1} / \bar{\phi}
$$

and vice versa when $f_{2}>f_{1}$. In summary, for given $f_{1}$ and $f_{2}$, the size of participating CPs in CNP $j$ is

$$
N_{j}^{s}=1-\frac{f_{j}}{\bar{\phi}}
$$

\subsection{Content Network Platforms}

CNPs' profits depend on the total volume of transactions between participating CPs and consumers. We assume that the volume has a one-to-one relationship with the size of participants in each CNP's network. Let $q_{i}$ be the last-mile access charge that CNPs need to pay to ISP $i$ under no regulation. Typically ISPs and CNPs do not share the same network members. Since CNPs' bandwidth usage in any given ISP network depends on the volume of transaction among the CNPs' network members, it is likely that the access charges will be set proportional to the volume of transactions that occur in each ISP's network. Then, each CNP's profit function can be written as

$$
\pi_{j}^{C N P}\left(f_{j}, f_{-j}\right)=\left(f_{j}-q_{1}\right) D_{1 j}^{e} N_{j}^{s}+\left(f_{j}-q_{2}\right) D_{2 j}^{e} N_{j}^{s}-C
$$

where $q_{i}, i=1,2$, is the last-mile access charge paid by the CNPs to ISP $i, D_{i j}^{e}$, $j=1,2$ is the expected consumer demand for the membership in $\mathrm{CNP} j$, and $C$ is the fixed cost.

The CNPs' problem is to determine the optimal advertising fee $f_{j}$ to charge the CPs. Given that both CNPs offer identical quality of service to consumers, a CNP's market power depends greatly on the network externality. Since consumers singlehome, CPs have to join both CNPs in order to reach their potential customers. Thus, while there is no differentiation in the quality of the service each CNP provides, each CNP exerts monopoly power over the multi-homing CPs so long as some consumers use its network, i.e., $E\left(N_{j}^{b}\right)>0$. 
From sections 3.1 and 3.2 , we know that if $f_{2} \geq f_{1}$ then $N_{1}^{s} \geq N_{2}^{s}$. In turn, $N_{1}^{b} \geq N_{2}^{b}$, only if consumers expect $E\left(N_{1}^{s}\right) \geq E\left(N_{2}^{s}\right)$, and vice versa. Especially, if consumers expects $f_{2}>f_{1}, N_{1}^{b}>N_{2}^{b}=0$. However, consumers never directly observe the advertising fees that CPs pay. Thus, they must guess the size of participating CPs in determining their platform. The following proposition shows that the unique Bayesian Nash equilibrium occurs when $E\left(N_{1}^{s}\right)=E\left(N_{2}^{s}\right)=N^{s}$, and the equilibrium advertising fee is the monopoly price $f=f_{1}=f_{2}$.

Proposition 1 The unique, symmetric equilibrium advertising fee, $f$, is the monopoly price which satisfies

$$
\begin{aligned}
\left.\frac{\partial \pi_{j}^{C N P}}{\partial f_{j}}\right|_{f_{j}=f} & =0 \Leftrightarrow N^{s} \sum_{i} D_{i j} \Lambda_{i}^{j}=0, \\
& \Leftrightarrow D_{1 j} \Lambda_{1}^{j}+D_{2 j} \Lambda_{2}^{j}=0,
\end{aligned}
$$

where $\Lambda_{i}^{j}=1-\left(f-q_{i}\right)\left[\frac{1}{\phi N^{s}}+\frac{\lambda \hat{\theta}_{-i}}{2 \phi D_{i j}}\right]$, for $i, j=1,2$.

Proof. All proofs are provided in Appendix B.

If $q_{1} \neq q_{2}, \Lambda_{1}^{j} \neq \Lambda_{2}^{j}$, and at the optimum, $\Lambda_{1}^{j}=-\frac{D_{2 j}}{D_{1 j}} \Lambda_{2}^{j}$. On the other hand, if $q_{1}=q_{2}, \Lambda_{1}^{j}=\Lambda_{2}^{j}$, and since it must be that $D_{i j}>0$ in equilibrium, the optimal fees must satisfy $\Lambda_{1}^{j}=\Lambda_{2}^{j}=0$. In either case, the equilibrium fees are symmetric. Moreover, the optimal $f$ is at the monopoly price. While the CNPs are in Bertrand competition with homogenous product, the two-sidedness of the market allows the CNPs monopoly power. This is because, in equilibrium, consumers' rational belief is that the size of participating CPs in each network has to be the same, which is possible only if the two CNPs offer the same price for advertising fees. Then, under the expectation of symmetric price, the optimal price is the monopoly price. Thus, whether one monopolist CNP serves the entire market or whether there is competition, it would not affect the market price. This result implies that adding more competing platforms at the CNP level or allowing a horizontal merger that leads to a monopoly at the CNP level would not affect the equilibrium advertising fees.

\subsection{Internet Service Providers}

Consumers subscribing to ISP $i$ pay a fixed monthly fee $p_{i}$ to connect to the Internet. Under non-neutrality, CNPs must pay $q_{i}$ to ISP $i$ to be able to get the last-mile access to consumers who are subscribing to this ISP. Therefore, the profit function for ISP $i$ is

$$
\pi_{i}^{I S P}=\left(D_{i 1}+D_{i 2}\right)\left(p_{i}-c_{0}+\left(q_{i}-2 c_{t}\right) N^{s}\right)-F,
$$


where $c_{0}$ is the marginal cost of providing Internet connection for consumers, $c_{t}$ is the one-way marginal cost of transmitting data traffic and $F$ is the fixed cost. ${ }^{6}$ For simplicity, assume that $c_{0}=c_{t}=0$.

The ISPs' problem is to set $\left\{\left(p_{i}^{*}, q_{i}^{*}\right)\right\}_{i=1,2}$, the optimal connection prices for consumers and the access charges for CNPs. ISPs have no incentive to lower the price below $\underline{p}=v-c+\lambda N^{s}$ since at $\underline{p}, \hat{\theta}_{i}=0$, thus lowering the price will not increase demand further. Hence, we will restrict the domain of $p$ in the range where $p_{i} \geq \underline{p}$. For the symmetric $f$, the optimal $p_{i}$ and $q_{i}$ satisfy

$$
\begin{aligned}
\frac{\partial \pi_{i}^{I S P}}{\partial p_{i}} & =\sum_{j} D_{i j}\left[1+q_{i} \frac{\partial N^{s}}{\partial f} \frac{\partial f}{\partial p_{i}}\right]+\frac{\partial \sum_{j} D_{i j}}{\partial p_{i}}\left(p_{i}+q_{i} N^{s}\right) \leq 0, \\
\frac{\partial \pi_{i}^{I S P}}{\partial q_{i}} & =\sum_{j} D_{i j}\left[N^{s}+q_{i} \frac{\partial N^{s}}{\partial f} \frac{\partial f}{\partial q_{i}}\right]+\frac{\partial \sum_{j} D_{i j}}{\partial q_{i}}\left(p_{i}+q_{i} N^{s}\right) \leq 0 .
\end{aligned}
$$

Let $\varepsilon_{i}^{p}=-\frac{\partial\left(D_{i 1}+D_{i 2}\right)}{\partial p_{i}} \cdot \frac{p_{i}}{\left(D_{i 1}+D_{i 2}\right)}$ and $\varepsilon_{i}^{q}=-\frac{\partial\left(D_{i 1}+D_{i 2}\right)}{\partial q_{i}} \cdot \frac{q_{i}}{\left(D_{i 1}+D_{i 2}\right)}$ denote the price elasticities of demand for ISP $i$ 's Internet connection with respect to the changes in $p_{i}$ and $q_{i}$, respectively.

If $p_{i}>\underline{p}, q_{i}>0, \varepsilon_{i}^{p} \neq 0$, and $\varepsilon_{i}^{q} \neq 0$, rearranging terms, we get

$$
\begin{aligned}
\frac{\left(p_{i}+q_{i} N^{s}\right)}{p_{i}} & =\frac{\left[1+q_{i} \frac{\partial N^{s}}{\partial f} \frac{\partial f}{\partial p_{i}}\right]}{\varepsilon_{i}^{p}} \\
\frac{\left(p_{i}+q_{i} N^{s}\right)}{q_{i} N^{s}} & =\frac{\left[1+q_{i} \frac{\partial N^{s} / \partial f}{N^{s}} \frac{\partial f}{\partial q_{i}}\right]}{\varepsilon_{i}^{q}} .
\end{aligned}
$$

Equations (18) and (19) show the role of CNPs in two-sided markets on the Internet. The ISPs' optimal pricing strategies, and thus the effectiveness of access regulation, depend on how access regulation affects CNPs' optimal fees from CPs. The two terms in (18) and (19), $\frac{\partial N^{s}}{\partial f} \cdot \frac{\partial f}{\partial p_{i}}$ and $\frac{\partial N^{s}}{\partial f} \cdot \frac{\partial f}{\partial q_{i}}$, appear due to the fact that CNPs have market power and, as platforms, they can optimally determine how much to absorb or amplify the impact of price changes by the ISPs before they transfer the changes to the CPs.

If $\frac{\partial f}{\partial p_{i}}<0$, this implies that when the consumer Internet price increases, the CNPs optimally lower the fees for CPs, offsetting the negative impact on consumers in order to optimize the size of network participants (since $\frac{\partial N^{s}}{\partial f} \cdot \frac{\partial f}{\partial p_{i}}>0$ ). In that case, from (18), other things being equal, the ISPs will be more inclined to set higher Internet prices for consumers. Similarly, if $\frac{\partial f}{\partial q_{i}}>0$, when access charges increase, the higher cost of operation for CNPs leads to higher advertising/listing fees for CPs. In the next section, we show that in a symmetric equilibrium, $\frac{\partial f}{\partial p}<0$ and $\frac{\partial f}{\partial q}>0$.

\footnotetext{
${ }^{6}$ Following the notations in Armstrong (2006), let group 1 and group 2 be consumers and CNPs, respectively. Then, our framework is one case of Armstrong (2006) where each ISP is competing with two-part tariffs $T^{l}=p^{l}+q^{l} N^{-l}$, for group $l=1,2$, and $q^{1}=p^{2}=0$.
} 


\section{$4 \quad$ Symmetric Equilibrium}

In this section, we derive a symmetric equilibrium with market determined access charges, which will be used as a benchmark to assess the impact of access regulation in the next section.

Consider a symmetric equilibrium where $p_{1}=p_{2}=p^{*} \geq \underline{p}$, and $q_{1}=q_{2}=q^{*} \geq 0$ in equilibrium. Then, $\hat{\theta}_{1}=\hat{\theta}_{2}=\hat{\theta}(v, c, \lambda, \bar{\phi})$ and $D_{i j}=D=1 / 4\left(1-\hat{\theta}^{2}\right)$. From (13), at the optimum, $\Lambda_{1}^{j}=\Lambda_{2}^{j}=0$. Thus, the optimal $f$ satisfies

$$
1-(f-q)\left[\sigma_{f}^{s}+\sigma_{f}^{b}\right]=0
$$

where $\sigma_{f}^{s}=-\frac{\partial N^{s} / \partial f}{N^{s}}=\frac{1}{\phi N^{s}}$ and $\sigma_{f}^{b}=-\frac{\partial D / \partial f}{D}=\frac{\lambda \hat{\theta}}{2 \dot{\phi} D}$ are the semi-elasticities of demand for CNPs' services by CPs and consumers, respectively. Let $\eta_{f}^{s}=-\frac{\partial N^{s} / \partial f}{N^{s}} f=$ $\sigma_{f}^{s} f$ and $\eta_{f}^{b}=-\frac{\partial D / \partial f}{D} f=\sigma_{f}^{b} f$ denote the elasticities of demand for CNPs' membership by consumers and CPs, respectively. Then, from equation (20), we obtain

$$
\frac{f-q}{f}=\frac{1}{\left(\eta_{f}^{s}+\eta_{f}^{b}\right)} .
$$

The optimal $f$ is determined in the region where $\eta_{f}^{b}+\eta_{f}^{s} \geq 1$. Equation (21) shows that the optimal fees depend on the overall elasticities of demand from both the consumer side and the CPs' side. Even if CPs' elasticity of demand is high, if the elasticity on the consumers' side is much lower, then the fees will be set high and vice versa.

Proposition 2 The optimal $f$ satisfies the following properties:

$$
\begin{gathered}
\frac{\partial f}{\partial p}<0 \\
0<\frac{\partial f}{\partial q}<\frac{1}{2}, \text { and } \\
\left|\frac{\lambda}{\bar{\phi}} \frac{\partial f}{\partial p}\right|<\frac{1}{2}
\end{gathered}
$$

CNPs react to the changes in $p$ and $q$ differently: they lower their fee if the Internet price for consumers increases $\left(\frac{\partial f}{\partial p_{i}}<0\right)$, while they increase their fee if the access charge increases $\left(\frac{1}{2}>\frac{\partial f}{\partial q_{i}}>0\right)$. Since CNPs do not charge consumers, the change in $p$ matters to CNPs only through its indirect effect on the volume of transaction. An increase in $p$ lowers the consumer incentive to join the network, and thus, if CNPs do not adjust their fee, there will be fewer consumers per CP, which lowers transaction volume and revenues. Hence, CNPs have the incentive to compensate consumers by 
lowering the fee and enhancing the network externality. On the other hand, in the case of an increase in $q$, given that access charges are marginal operating costs for CNPs, it leads to an increase in the fee. However, the burden of higher access charges is not fully transferred to CPs since $\frac{1}{2}>\frac{\partial f}{\partial q_{i}}$ and CNPs partially absorb the effect of an increase in costs.

From (19), since $\frac{\left(p_{i}+q_{i} N^{s}\right)}{q_{i} N^{s}}>1$ and $\frac{\partial N^{s} / \partial f}{N^{s}} \cdot \frac{\partial f}{\partial q_{i}}<0$, in equilibrium, the optimal access charges are set in the range where $\varepsilon_{i}^{q}<1$. Imposing symmetry on the consumer prices and access charges, we can rewrite the equations (16) and (17) as

$$
\begin{aligned}
\frac{\partial \pi_{i}^{I S P}}{\partial p_{i}} & =\frac{1}{2}\left(1-\hat{\theta}^{2}\right)\left(1-\frac{q}{\bar{\phi}} \frac{\partial f}{\partial p}\right)-\left(p+q N^{s}\right)\left(1+\frac{\lambda \hat{\theta}}{\bar{\phi}} \frac{\partial f}{\partial p}\right) \leq 0 \\
\frac{\partial \pi_{i}^{I S P}}{\partial q_{i}} & =\frac{1}{2}\left(1-\hat{\theta}^{2}\right)\left(N^{s}-\frac{q}{\bar{\phi}} \frac{\partial f}{\partial q}\right)-\left(p+q N^{s}\right)\left(\frac{\lambda \hat{\theta}}{\bar{\phi}} \frac{\partial f}{\partial q}\right) \leq 0
\end{aligned}
$$

There are two types of equilibria: when the market demand for the Internet is fully covered, $\hat{\theta}=0$, and when the demand is not fully covered, $0<\hat{\theta}<1$. The market demand for the Internet is likely to be fully covered, $\hat{\theta}=0$, when $v-c$ and $\bar{\phi}$ are high. ${ }^{7}$ When $v-c$ is very high, consumers derive a great utility from network service provided by the CNPs and ISPs, and thus, all consumers would like to buy the Internet connection. A similar situation occurs if the profitability of CPs $\bar{\phi}$ is large enough. When $\bar{\phi}$ is high, having many consumers on board is important for the ISPs to be able to extract rent from CNPs through access charges. Thus, ISPs offer consumers a low Internet price so that they can have the largest source of access revenue.

When the market is fully covered, the effect of open access regulation is somewhat straightforward: as long as the market demand remains fully covered, access regulation increases the transaction volume by inducing a greater participation from CPs. Thus, access regulation improves welfare. ${ }^{8}$

On the other hand, if $\bar{\phi}$ or $v-c$ is not too large, $0<\hat{\theta}<1$. In this case, consumer demand for the Internet depends on the access charges, and ISPs' Internet pricing depends on how much rent they can extract from CNPs through access charges. For this reason, our analysis focuses on this case when the market is not fully covered.

\section{The Effects of Access Regulation}

In this section, we analyze how access regulation alters the optimal pricing strategies of the ISPs and welfare. For simplicity, we consider a fixed symmetric access charge

\footnotetext{
${ }^{7}$ See Appendix B 9.3 for detailed conditions under which the market becomes fully covered.

${ }^{8}$ The welfare analysis of access regulation for the cases when the market is initially fully covered is provided in the supplementary Technical Appendix.
} 
$a \geq 0$ per transaction. In the context of open access regulation, this fixed access charge can be understood as a government sanctioned upper limit on the access charges over Internet traffic. If $a \geq q^{*}$, regulation is not binding, and there is no difference whether the access charges are regulated or not. Regulation has an effect on the market only if $a<q^{*}$. Thus, we only focus on this case. ${ }^{9}$

Timing of the modified game under regulation is as follows. In stage 0 , the government sets the access charge. In stage 1 , ISPs determine the Internet price. In stage 2, CNPs choose the fees, and in stage 3, consumers and CPs make their choices.

\subsection{Open Access Regulation}

\subsubsection{The effect on consumer Internet prices}

For a given $a>0$, the behaviors of consumers, CPs, and CNPs are the same as before in the sense that $(8),(9),(10),(11)$, and (13) are the same except that they are now functions of $a$ instead of $q$. The CNP's optimal fee satisfies

$$
1-\left(f_{a}-a\right)\left[\sigma_{f}^{s}+\sigma_{f}^{b}\right]=0 .
$$

The profit function for ISP $i$ is rewritten as

$$
\pi_{i a}^{I S P}=\left(D_{i 1}+D_{i 2}\right)\left(p_{i}+a N^{s}\right)-F .
$$

The optimal symmetric Internet price $p_{1}=p_{2}=p_{a} \geq \underline{p}$ satisfies

$$
\frac{1}{2}\left(1-\hat{\theta}^{2}\right)\left(1-\frac{a}{\bar{\phi}} \frac{\partial f}{\partial p}\right)-\left(p+a N^{s}\right)\left(1+\frac{\lambda \hat{\theta}}{\bar{\phi}} \frac{\partial f}{\partial p}\right) \leq 0 .
$$

Let $\gamma_{p}=\left(\frac{\partial N^{s}}{\partial p}\right) \frac{p}{N}=\left(\frac{-1}{\phi} \frac{\partial f}{\partial p}\right) \frac{p}{N}>0$ and $\gamma_{a}=-\left(\frac{\partial N^{s}}{\partial a}\right) \frac{a}{N}=\left(\frac{1}{\phi} \frac{\partial f}{\partial a}\right) \frac{a}{N}>0$ denote the elasticities of CPs' network participation with respect to the consumer Internet price and access charge evaluated at the market equilibrium $p^{*}$, and $a=q^{*}$. Then, Proposition 3 shows that, depending on $\gamma_{p}$ and $\gamma_{a}$, lowering access charges can also lower consumer Internet prices.

\footnotetext{
${ }^{9}$ Thus, we only consider the case when $q^{*}>0$. In Appendix B 9.3, however, we show that for a small enough $\bar{\phi}$ and $v-c$, there is a range where $q^{*}=0$. This is because when $\hat{\theta}>0$, an increase in access charges lowers consumer demand $\left(\partial\left(D_{i 1}+D_{i 2}\right) / \partial q<0\right)$ by lowering network externality since it increases the CNPs' fees from CPs $\left(\frac{\partial f}{\partial q}>0\right)$. Therefore, when $\hat{\theta}_{i}>0$, an increase in $q$ lowers not only the size of participating CPs, but also the consumer demand for Internet. If the profits from access revenues are not significant while consumer demand reduces drastically as a result of a small increase in access charges, ISPs may not pursue access revenues. Instead, they can maximize revenues from consumer membership fees. In this case, ISPs may voluntarily set $q^{*}=0$ and forgo access revenues in order to minimize the negative impact on consumer demand.
} 
Proposition 3 Suppose $a>0$ and $\hat{\theta}>0$. Lowering a below $q^{*}$ reduces $p$ if and only if

$$
\gamma_{p}\left(1+\kappa \gamma_{a} \frac{\left(\gamma_{p}-1\right)}{\left(\varepsilon_{p}-1\right)}\right)>2 \varepsilon_{p}\left(1-\gamma_{a}\right),
$$

where $0<\gamma_{a}<1$ and $\kappa=\frac{\lambda N^{s 2}}{2 D}$.

Equations (18) and (19) show how the Internet price and access charges are related. In general, in a two-sided market, when a factor generates a higher price on one side, it tends to lower the price on the other side. Hence, if not for the effect of the two terms $\frac{\partial f}{\partial p_{i}}$ and $\frac{\partial f}{\partial q_{i}}$, according to this "seesaw principle," access regulation that lowers CPs' prices is expected to increase consumer Internet prices.

However, this paper shows that depending on how the CNPs adjust their fees in response to the ISPs' price changes, the "seesaw principle" may not hold. Proposition 3 shows that $\frac{d p}{d a}>0$ is more likely to hold as $\gamma_{p}$ and $\gamma_{a}$ are higher. CNPs lower the fees they charge CPs if $p$ increases while they increase the fees if $q$ increases. Thus, other things being equal, the higher $\gamma_{p}$ is, the less costly it is for ISPs to increase consumer Internet prices than to increase access charges. This is especially true if consumer Internet demand is less responsive to the Internet price changes than the participation of CPs while an increase in access charge induces a steeper rise in advertising fees (a higher $\gamma_{a}$ ). In this case, in order to increase the transaction volume and thus access revenues, ISPs would have incentives to charge a high $p$ for consumers to induce lower advertising fees from CNPs without lowering their access charges $q$ much. In this situation, limiting the level of access revenues ISPs can raise, access regulation lowers ISPs' incentives to charge a high $p$ to optimize access revenues. Thus, ISPs lower Internet price as a result of access regulation. By contrast, in other models of platform competition on the Internet where the role of CNPs is not considered, $\gamma_{p}=0\left(\frac{\partial f}{\partial p}=0\right)$ and thus, $\frac{d p}{d a}<0$ always.

\subsubsection{The effect on advertising fees}

Since $\frac{d f}{d a}=\frac{\partial f}{\partial a}+\left(\frac{\partial f}{\partial p}\right) \frac{d p}{d a}$, if $\frac{d p}{d a}<0$, lowering access charges lowers advertising fees. If $\frac{d p}{d a}>0$, on the other hand, the effect of access regulation on advertising fees is not straightforward. A decrease in access charges directly decreases the fees, $\frac{\partial f}{\partial a}>0$, while it indirectly increases the fees through the effect on consumer Internet price, $\left(\frac{\partial f}{\partial p}\right) \frac{d p}{d a}<0$. However, we find that the direct effect dominates the indirect effect in equilibrium.

Proposition 4 Regardless of the effect on p, access regulation lowers advertising fees $f$. 


\subsubsection{The effect on Welfare}

While access regulation unambiguously improves the market conditions for CPs, and enhances network externalities that consumers receive as well by inducing greater participation from CPs, the final effect on consumer demand for the Internet is still ambiguous. Other existing models of net neutrality report a similar ambiguous effect on consumer demand mainly because consumer prices unambiguously increase in those models. However, in this paper, the effect on consumer demand is more likely to be favorable due to the possibility that access regulation can in fact lower consumer prices. Consumer demand increases as a result of access regulation when $\frac{d \hat{\theta}}{d a}>0$. Since $\frac{d \hat{\theta}}{d a}=\frac{d p}{d a}+\frac{\lambda}{\phi} \frac{d f}{d a}$ and access regulation lowers advertising fees and thus improves the network externality for consumers $\left(\frac{\lambda}{\phi} \frac{d f}{d a}>0\right)$, if the price is lower $\left(\frac{d p}{d a}>0\right)$, consumer demand unambiguously increases, $\frac{d \hat{\theta}}{d a}>0$

Moreover, we find that the welfare implication of access regulation ultimately depends on how it affects consumer demand for the Internet. For a given $a$, total welfare is calculated as

$$
\begin{aligned}
W & =2 \int_{\hat{\theta}}^{1}(\theta-\hat{\theta}) d \theta+2 N^{b} \int_{f}^{\bar{\phi}} \frac{(\phi-f)}{\bar{\phi}} d \phi+2 \pi^{C N P}+2 \pi^{I S P} \\
& =\underbrace{(1-\hat{\theta})^{2}}_{\text {consumer surplus }}+\underbrace{2 N^{b} \int_{f}^{\bar{\phi}} \frac{\phi}{\bar{\phi}} d \phi}_{\text {CP's surplus }}+\underbrace{2 N^{b} p}_{\text {ISPs' membership revenues }}-2 C-2 F \\
& =(1-\hat{\theta})^{2}+2 N^{b} \int_{f}^{\left(\int_{f}^{\bar{\phi}} \frac{\phi}{\bar{\phi}} d \phi+p\right)}-2 C-2 F \\
& =(1-\hat{\theta})^{2}+\left(1-\hat{\theta}^{2}\right)\left(\frac{(\bar{\phi}+f)}{2} N^{s}+p\right)-2 C-2 F .
\end{aligned}
$$

Thus,

$$
\frac{d W}{d a}=\underbrace{\left[2(1-\hat{\theta})+2 \hat{\theta}\left(\frac{\bar{\phi}^{2}-f^{2}}{2 \bar{\phi}}+p\right)\right]}_{A}\left(-\frac{d \hat{\theta}}{d a}\right)+\left(1-\hat{\theta}^{2}\right)\left(\frac{d p}{d a}-\frac{f}{\bar{\phi}} \frac{d f}{d a}\right) .
$$

Proposition 5 A lower access charge a $<q^{*}$ improves total welfare as long as consumer demand for the Internet does not decrease.

If consumer prices decrease, then access regulation induces greater participation not only from CPs, but also from consumers. Then, the increased transaction volume 
further enhances the profits for CPs, and the profits losses for ISPs will be minimal. Therefore, in this case, access regulation unambiguously increases welfare. From Proposition 3, access regulation lowers the price for consumers $\left(\frac{d p}{d a}>0\right)$ and thus unambiguously increases demand for the Internet if $\gamma_{a}$ and $\gamma_{p}$ are sufficiently high. Thus, if $\gamma_{a}$ and $\gamma_{p}$ are high, access regulation is more likely to improve welfare.

Corollary 1 Access regulation is more likely to improve welfare for high $\gamma_{p}$ and $\gamma_{a}$.

Even if consumers pay higher prices after regulation $\left(\frac{d p}{d a}<0\right)$, it does not necessarily result in lower consumer demand for the Internet. This is because in addition to the price, network externality is an important factor that determines the demand. As access regulation lowers the fees for CPs, more CPs are expected to join the network, which increases network externality for consumers and thus their willingness to join the network. If the increase in network externality outweighs the price effect, consumer demand for the Internet can increase even if the prices are higher. That is, it can be that $\frac{d \hat{\theta}}{d a}=\frac{d p}{d a}+\frac{\lambda}{\phi} \frac{d f}{d a}>0$ even if $\frac{d p}{d a}<0$ as long as $\frac{\lambda}{\phi} \frac{d f}{d a}>\left|\frac{d p}{d a}\right|$.

Proposition 5 implies that, in general, welfare improvement in the two-sided market requires increased transaction volume. In our framework, given the assumption that the transaction volume is proportional to the size of participants from each side, greater participation from both sides of the market ensures welfare improvement. Lower access charges directly enhance market conditions for CPs and thus induce greater participation of CPs. Yet, the effect on consumer demand is ambiguous. Therefore, naturally, the effectiveness of access regulation depends on how it affects consumer demand for the Internet.

In the National Broadband Plan issued in 2010, the FCC cites that "nearly 100 million Americans do not have broadband," and states that "[t]he mission of the plan is to create a high-performance America [...] in which affordable broadband is available everywhere and everyone has the means and skills to use valuable broadband applications." To achieve this goal, the plan recommends designing "policies to ensure robust competition and, as a result, maximize consumer welfare." 10 Therefore, net neutrality regulation specifically aims to enhance competition in the content markets in order to increase demand for Internet services and deployment of broadband service.

The rationale behind the recommendation is that net neutrality regulation effectively increases the availability and affordability of broadband by promoting competition in the content markets, and that an increase in consumer demand for the Internet is crucial in enhancing welfare. We find that access regulation may not necessarily induce higher demand for Internet services, but if it does, it improves total welfare.

On the other hand, if access regulation increases the Internet prices, it may reduce consumer demand substantially. Moreover, if the decrease in transaction volume is

\footnotetext{
${ }^{10}$ The National Broadband Plan, July 2010, http://www.broadband.gov/.
} 
significant, despite lower access charges, CPs' surplus may decrease after all as a result of access regulation because of the decrease in transaction volume. That is, while there are more CPs in the market, each CP makes less profit than it did before regulation. Proposition 6 shows that welfare can decrease in this case.

Proposition 6 Access regulation lowers welfare if $\frac{d p}{d a}<0$ and $\left|\frac{d p}{d a}\right|>\frac{X\left(\frac{\partial f}{\partial a}\right)}{A-\left(1-\hat{\theta}^{2}\right)+X\left(\frac{\partial f}{\partial p}\right)}>$ 0 , where $A=2(1-\hat{\theta})+2 \hat{\theta}\left(\frac{\bar{\phi}^{2}-f^{2}}{2 \phi}+p\right)>0$, and $X=\frac{\lambda}{\phi}\left(A+\left(1-\hat{\theta}^{2}\right) \frac{f}{\lambda}\right)>0$.

Corollary 2 Access regulation is more likely to lower welfare for low $\gamma_{p}$ and $\gamma_{a}$.

These results from Propositions 3 through 6 and Corollaries 1 through 2 imply that in general in two-sided markets, the effectiveness of regulation that aims to stimulate one-side (CPs) depends on whether it can also stimulate the participation of the other side (consumers). To ensure that one-sided regulation is in fact an effective way of regulating the Internet, the regulatory authorities must make sure that the impact on the other side is not substantially negative. Otherwise, an alternative regulatory instrument should be considered.

\subsection{Effects of Zero Access Charges}

Now consider the case where ISPs are not allowed to charge any for the last mile access. The results in section 5.1 can be easily extended to the case of net neutrality. Let $p_{N}$ be the price of the Internet connection under net neutrality $(a=0)$ and let $\gamma_{p_{N}}=\left(\frac{-1}{\phi} \frac{\partial f}{\partial p}\right) \frac{p_{N}}{N^{s}}>0$ be the elasticity of CPs' participation with respect to the Internet price evaluated at $p_{N}$ and $a=0$.

Corollary 3 1. Net neutrality lowers both the fees from CPs and the consumer Internet price if $\gamma_{p_{N}} \geq 1=\varepsilon_{P N}$.

2. Net neutrality improves welfare if $\gamma_{p_{N}} \geq 1=\varepsilon_{P N}$.

3. Net neutrality is more likely to reduce welfare if $\gamma_{p_{N}}$ is low.

\section{Discussion}

In this section, we discuss the mechanism through which access charges influence market outcomes in our model, why its results differ from those of other models, the implications of open access regulation in this framework, and how access regulation of the Internet differs from that of traditional telecommunications. 


\subsection{The Role of the CNPs and Access Charges}

In the current framework, we have two vertical layers of monopolistic platforms: the CNPs and the ISPs. The unique role of CNPs is explicitly shown in the structure of how optimal advertising fees are affected by ISPs' Internet prices and access charges, given in (22) and (23). These equations determine the relationship between access charges and consumer demand for the Internet, which account for the differences between the results of our paper and other models.

For example, we find that lower access charges can lower the consumer Internet price as well as the advertising fees for CPs (Proposition 3), while all other existing models predict that consumer price will increase as a result of lowering access charges. This is because in our model, ISPs' pricing depends on how CNPs respond to Internet price changes. What makes a difference is not that CNPs have market power but that CNPs are the platforms between consumers and CPs. If CNPs are just firms that have market power but do not play the role of the platforms, then CNPs have no reason to consider the impact of consumer Internet prices in determining their fees for CPs, and thus, $\frac{\partial f}{\partial p}=0$ while $\frac{\partial f}{\partial q}>0$ still holds. This is how CNPs are typically viewed in existing net neutrality literature. When the CNPs are understood as platforms, however, we can identify another channel of reaction generated by access regulation. CNPs optimally absorb the impact of an increase in Internet price by lowering their fees $\left(\frac{\partial f}{\partial p}<0\right)$. Knowing this, ISPs in general have more incentive to set a high price for the Internet when they are allowed to charge for access. Regulating access charges reduces the ISPs' incentive to set a high price for the Internet. Thus, it would not only decrease the access charges for CNPs, also decrease the consumer Internet price.

More importantly, because of the CNPs' response to the changes in consumer prices, access regulation on the Internet is more likely to be efficient. Consumer prices can go down because $\frac{\partial f}{\partial p}<0$. Total welfare improves if consumer prices are lower and thus the demand is higher. Thus, access regulation is more likely to be welfare-improving as a result of CNPs' involvement. This indicates that the welfare implication of access regulation crucially depends on how CNPs would respond to the changes in access charges and Internet prices.

\subsection{Open Access Regulation on the Internet}

Some claim that net neutrality only determines how the ISPs and the CNPs (or the CPs) divide their profits, but does not affect consumers, and hence, there is no need for regulation. Others argue that the only reason for regulation is that the unregulated market solution might allow too much rent extraction by the ISPs and lead to the foreclosure of competition at the CNP level. In order to minimize the potential harm on the CNPs (and ultimately the CPs), they propose open access regulation instead of extensive net neutrality regulation. 
Our model shows that access regulation on the Internet is more than just about how ISPs and CNPs divide their profits. Given that ISPs and CNPs are monopoly bottlenecks, in some range of parameters, there is a potential welfare gain from access regulation.

Concerned about the possibility of using access charges to foreclose competition, some proponents of net neutrality further argue that the Internet should be reclassified as telecommunications so that the FCC can have full authority to regulate the market. For this reason, we would like to briefly discuss how Internet access regulation is different from the access regulation in telecommunications.

In the case of traditional one-way access pricing in telecommunications, the need for regulation arises since there is no private incentive for the monopoly bottleneck to provide access at a fair price to rivals. Thus, without regulation, potentially efficiency improving entries are deterred. By contrast, on the Internet, in most cases, ISPs and CNPs are not in direct competition with each other. The services provided by ISPs and CNPs are perfectly complementary. Moreover, ISPs normally do not have incentives to charge an exorbitant price for access to foreclose competition. This is because such foreclosure would be feasible only if local ISPs also have a comparable national network that CNPs have. Currently, not many local ISPs qualify. As Weisman and Kulick (2010) states, "ISPs generally serve regional markets whereas content markets are often national or international." Without having a comparable level of facility to replace CNPs' services, the ISPs may not be able to foreclose CNPs. When foreclosure is not possible, ISPs incur losses if access charges are set too high, especially when an increase in access charges lowers their access revenues a lot by lowering transaction volume. For example, if $v-c$ and $\bar{\phi}$ are very low, ISPs may even optimally charge zero for access in order to boost the transaction volume.

However, in some industries such as online movies and VOIP services, vertical integrations between ISPs and CNPs have already taken place or are easy to obtain. Naturally, our model does not apply to these industries. For example, Comcast's on-demand movies are in direct competition with Netflix online movies. Also, as in the case of Vonage v. Madison River Communications, the VOIP service provider (Vonage) and the local ISP (Madison River Communications) are in direct competition over the provision of telephony services and the VOIP service provider must have access to the local ISP's network to be able to compete with the local ISP. In these industries, an ISP is vertically integrated with either a CNP or with another downstream market platform and vertically integrated ISPs do have incentives to use access charges as an instrument for foreclosure.

Even in the markets where foreclosure is not an immediate concern because currently not many local ISPs have national or international level of networks, some local ISPs are the subsidiaries of larger national ISPs such as AT\&T and Comcast. If these local ISPs continue to expand their network and become able to offer equivalent level of network services that CNPs provide, given the perfect complementarity 
of the services, vertical integration between ISPs and CNPs seems to be the logical choice as in the case of Comcast and NBC Universal merger (The New York Times, January 19, 2011, "Comcast Receives Approval for NBC Universal Merger"). Then, the vertically integrated ISPs would have incentives to use access charges to foreclose competition in the absence of access regulation. In this case, the implication of access regulation would be quite different. Weyl (2008) provides insight to how such a vertical integration between upstream and downstream platforms would affect the market outcomes. Yet, it remains uncertain how access regulation would affect the incentives for the vertical integration between platforms and how the welfare implication of access regulation would change as a result. We discuss these issues in a separate companion paper.

\section{Conclusion}

In this paper, we consider a two-sided market framework where consumers and content providers interact via CNPs. Local ISPs provide an essential input: the Internet connection for consumers and the last-mile access for the CNPs. We assess the effectiveness of open access regulation by analyzing how lowering the ISPs' last-mile access charges below the market equilibrium level affects welfare.

We find that the effect of access regulation on consumer demand for the Internet depends on how sensitively CNPs respond to the changes in ISPs' prices, which in turn depends on how sensitively CPs' network participation responds to the resulting changes in advertising fees, in comparison with consumer demand elasticities with respect to the Internet price and network externality. We find that the "seesaw principle" may not hold, depending on how CNPs respond to ISPs' price changes. Therefore, in some cases, access regulation may induce lower prices for both CPs and consumers and unambiguously improve welfare. However, in other ranges of parameters, lower access charges may induce higher Internet prices for consumers. If consumer Internet demand decreases substantially as a result, CPs becomes worse off even if they pay lower fees to CNPs because their profits are lower due to lower transaction volume. In this case, access regulation lowers welfare.

The effectiveness of access regulation indeed greatly depends on how it affects consumer demand for the Internet. Access regulation is effective only if its impact on the consumer side is not too negative. The main results of this paper suggest that access regulation should be implemented only if there is empirical evidence indicating that CPs' participation is more elastic than consumer demand to the changes in the Internet prices and access charges. Hence, in order to assess the FCC's national broadband plan that aims to achieve a greater level of market coverage through access regulation, it would be necessary to get an empirical validation of current market conditions about the elasticities of consumer demand and CPs' participation. However, a more important question would be whether access regulation is the most 
efficient way of regulating the Internet. We argue that in general, it is difficult to improve welfare from both sides using "one-sided" regulation.

\section{Appendix A: Single-homing consumers and multi- homing CPs}

In this Appendix, we prove that consumers single-home and CPs multi-home in equilibrium. The description of consumer demand and CPs' supply decisions when consumers single-home is given in sections 3.1 and 3.2. Now suppose consumers multihome.

From (3), consumers multi-home only if $\bar{N}^{s}>N_{j}^{s}$ for all $j=1,2$, and $c_{12}-c$ is small enough. In this case, consumers purchase an Internet connection as long as $u_{i 12}=\theta_{i}+\nu+\lambda \bar{N}^{s}-p_{i}-c_{12} \geq 0$. That is, as long as $\theta_{i} \geq p_{i}-\tilde{x} \equiv \tilde{\theta}_{i}$ every consumer in each ISP network subscribes to both CNPs, where $\tilde{x}=\nu-c_{12}+\lambda \bar{N}^{s}$. Thus, $\tilde{N}_{1}^{b}=\tilde{N}_{2}^{b}=\left(1-\tilde{\theta}_{1} \tilde{\theta}_{2}\right)$.

When consumers multi-home, content provider $k$ 's profits from single-homing is

$$
\pi_{k}^{C P}=\max \left\{\left(\phi_{k}-f_{1}\right) \tilde{N}^{b},\left(\phi_{k}-f_{2}\right) \tilde{N}^{b}, 0\right\} .
$$

On the other hand, if content provider $k$ multi-homes, the chance to receive consumers' click through either CNP 1 or 2 is evenly divided among the entire consumers $\tilde{N}^{b}$, thus, the provider $k$ earns

$$
\pi_{k m}^{C P}=\max \left\{\left(\phi_{k}-\left(f_{1}+f_{2}\right) / 2\right) \tilde{N}^{b}, 0\right\}
$$

Thus, if $f_{1} \neq f_{2}$, CPs single-home when consumers multi-home. However, if $f_{1}=f_{2}=f$, CPs get the same profits from either single-homing or multi-homing. We assume that CPs multi-home in this case. In summary, when consumers multihome, the provider $k$ joins CNP $j$ if and only if $f_{j^{\prime}} \geq f_{j}\left(j^{\prime} \neq j\right)$, resulting in

$$
N_{j}^{s}= \begin{cases}1-\frac{f_{j}}{\phi} & \text { if } f_{j^{\prime}} \geq f_{j}, \\ 0 & \text { if } f_{j^{\prime}}<f_{j} .\end{cases}
$$

Combining the results from the sections 3.1 and 3.2 and the result from above, we can easily show that consumers single-home in equilibrium. For consumers to multi-home, it must be that the two CNPs have a different group of CPs so that $0<$ $c_{12}-c<\lambda\left(\bar{N}^{s}-N^{s}\right)$. However, when consumers multi-home, from (34), we find that if $f_{j^{\prime}} \geq f_{j}, \bar{N}^{s}=N^{s}=N_{j}^{s}$, and if $f_{j^{\prime}}<f_{j}, \bar{N}^{s}=N^{s}=N_{j^{\prime}}^{s}$, for $j, j^{\prime}=1,2\left(j^{\prime} \neq j\right)$, and thus, $c_{12}-c>\lambda\left(\bar{N}^{s}-N^{s}\right)=0$. Therefore, consumers have no incentives to multi-home. As consumers single-home, the CPs multi-home in equilibrium. Q.E.D. 


\section{Appendix B}

\section{Proof of Proposition 1}

In stage 3, the unique Bayesian Nash equilibrium arises when consumers expect the same size of network in both CNPs, i.e., $E\left(N_{1}^{s}\right)=E\left(N_{2}^{s}\right)=N^{s}$. This requires that $f_{1}=f_{2}=f$. Then, we get $D_{i j}^{e}=D_{i j}$. Solving backward, in stage 2, each CNP's problem is then to choose the optimal $f$ given that $f_{1}=f_{2}=f$.

Let $f$ be the optimal symmetric price that maximizes the CNP $j$ 's profit $\pi_{j}^{C N P}(f)$ when $f_{1}=f_{2}=f$. Then, $f=\arg \max \left\{\left(f-q_{1}\right) D_{11} N^{s}+\left(f-q_{2}\right) D_{21} N^{s}\right\}$, where $D_{i j}$ are given by (8) and (9). Since $N^{s}=1-f / \bar{\phi}$, and from (8) and (9), $\frac{\partial D_{1 j}}{\partial f}=$ $\frac{\partial D_{1 j}}{\partial N^{s}} \cdot \frac{\partial N^{s}}{\partial f}=-\frac{\lambda \hat{\theta}_{2}}{2 \phi}$, and $\frac{\partial D_{2 j}}{\partial f}=\frac{\partial D_{2 j}}{\partial N^{s}} \cdot \frac{\partial N^{s}}{\partial f}=-\frac{\lambda \hat{\theta}_{1}}{2 \phi}$. Then, $f$ satisfies the following condition:

$$
\begin{aligned}
& \left.\frac{\partial \pi_{j}^{C N P}}{\partial f}\right|_{f_{1}=f_{2}=f}=0 \\
& \Leftrightarrow D_{1 j}\left[1-\frac{\left(f-q_{1}\right)}{\bar{\phi} N^{s}}-\frac{\lambda \hat{\theta}_{2}}{2 \bar{\phi}} \frac{\left(f-q_{1}\right)}{D_{1 j}}\right]+D_{2 j}\left[1-\frac{\left(f-q_{2}\right)}{\bar{\phi} N^{s}}-\frac{\lambda \hat{\theta}_{1}}{2 \bar{\phi}} \frac{\left(f-q_{2}\right)}{D_{2 j}}\right]=0 .
\end{aligned}
$$

Now, let $\hat{f}$ be the optimal monopoly price maximizing the monopoly profit for CNP $1, \pi_{1}^{M C N P}(f)$, i.e.,

$$
\hat{f}=\arg \max \left\{\left(f_{1}-q_{1}\right) D_{11}^{M} N_{1}^{s}+\left(f_{1}-q_{2}\right) D_{21}^{M} N_{1}^{s}\right\} .
$$

Then,

$$
\frac{\partial \pi_{1}^{M C N P}}{\partial f_{1}}=\left.0 \Leftrightarrow 2 \frac{\partial \pi_{j}^{C N P}}{\partial f}\right|_{f_{1}=f_{2}=f}=0 .
$$

That is, the condition for optimal $\hat{f}$ is identical with the condition for the symmetric solution $f$. Thus, the equilibrium symmetric fee $f$ is the monopoly price.

\section{Proof of Proposition 2}

From (13), by the Implicit Function Theorem,

$$
\begin{aligned}
& \frac{\partial f}{\partial p_{i}}=\frac{1}{-S O C_{f}}\left[\begin{array}{c}
D_{i j}\left(f-q_{i}\right) \frac{\lambda \hat{\theta}_{-i}}{2 \phi D_{i j}^{2}} \frac{\partial D_{i j}}{\partial p_{i}} \\
-D_{-i j}\left(f-q_{-i}\right)\left(\frac{\lambda}{2 \phi D_{-i j}}-\frac{\lambda \hat{\theta}_{i}}{2 \phi D_{-i j}^{2}} \frac{\partial D_{-i j}}{\partial p_{i}}\right) \\
+\frac{\partial D_{1 j}}{\partial p_{i}} \Lambda_{1}^{j}+\frac{\partial D_{2 j}}{\partial p_{i}} \Lambda_{2}^{j}
\end{array}\right] \text {, and } \\
& \frac{\partial f}{\partial q_{i}}=\frac{1}{-S O C_{f}}\left(D_{i j}\right)\left[\frac{1}{\bar{\phi} N^{s}}+\frac{\lambda \hat{\theta}_{-i}}{2 \bar{\phi} D_{i j}}\right] \text {, }
\end{aligned}
$$


where

$$
S O C_{f}=\left[\frac{\partial D_{1 j}}{\partial f} \Lambda_{1}^{j}+\frac{\partial D_{2 j}}{\partial f} \Lambda_{2}^{j}\right]+\left[D_{1 j} \frac{\partial \Lambda_{1}^{j}}{\partial f}+D_{2 j} \frac{\partial \Lambda_{2}^{j}}{\partial f}\right] .
$$

Since $\Lambda_{i}^{j}=0$, and $D_{i j}=D$ in symmetric equilibrium, we can rewrite the conditions as

$$
\begin{aligned}
\frac{\partial f}{\partial p} & =\frac{-1}{\left(-S O C_{f}\right)\left(\sigma_{f}^{s}+\sigma_{f}^{b}\right)}\left[\frac{\lambda \hat{\theta}^{2}}{4 \bar{\phi} D}+\frac{\lambda}{2 \bar{\phi}}\right]<0, \text { and } \\
\frac{\partial f}{\partial q} & =\frac{D}{\left(-S O C_{f}\right)}\left[\sigma_{f}^{s}+\sigma_{f}^{b}\right]>0,
\end{aligned}
$$

where

$$
\begin{aligned}
-S O C_{f} & =-\left[D_{1 j} \frac{\partial \Lambda_{1}^{j}}{\partial f}+D_{2 j} \frac{\partial \Lambda_{2}^{j}}{\partial f}\right] \\
& =\frac{2 D}{\left(\sigma_{f}^{s}+\sigma_{f}^{b}\right)}\left[\left(\sigma_{f}^{s}+\sigma_{f}^{b}\right)^{2}+\left(\sigma_{f}^{s}\right)^{2}+\left(\sigma_{f}^{b}\right)^{2}+\frac{\lambda^{2}}{2 \bar{\phi}^{2} D}\right]>0 .
\end{aligned}
$$

Thus,

$$
\begin{aligned}
& \frac{\partial f}{\partial p}=-\frac{1}{2} \frac{\left[\frac{\lambda \hat{\theta}^{2}}{4 \phi D^{2}}+\frac{\lambda}{2 \phi D}\right]}{\left[\left(\sigma_{f}^{s}+\sigma_{f}^{b}\right)^{2}+\left(\sigma_{f}^{s}\right)^{2}+\left(\sigma_{f}^{b}\right)^{2}+\frac{\lambda^{2}}{2 \bar{\phi}^{2} D}\right]}<0, \text { and } \\
& \frac{\partial f}{\partial q}=\frac{1}{2} \frac{\left(\sigma_{f}^{s}+\sigma_{f}^{b}\right)^{2}}{\left[\left(\sigma_{f}^{s}+\sigma_{f}^{b}\right)^{2}+\left(\sigma_{f}^{s}\right)^{2}+\left(\sigma_{f}^{b}\right)^{2}+\frac{\lambda^{2}}{2 \bar{\phi}^{2} D}\right]}<\frac{1}{2} .
\end{aligned}
$$

The regularity condition requires that $\left(1+\frac{\lambda}{\phi} \frac{\partial f}{\partial p}\right)>0$. Since

$$
\left|\frac{\lambda}{\bar{\phi}} \frac{\partial f}{\partial p}\right|=\left|-\frac{1}{2} \frac{\frac{\lambda^{2}}{2 \bar{\phi}^{2} D}\left[1+\frac{\hat{\theta}^{2}}{2 D}\right]}{\left[\left(\sigma_{f}^{s}+\sigma_{f}^{b}\right)^{2}+\left(\sigma_{f}^{s}\right)^{2}+\frac{\lambda^{2}}{2 \bar{\phi}^{2} D}\left(1+\frac{\hat{\theta}^{2}}{2 D}\right)\right]}\right|<\frac{1}{2}
$$

the condition is satisfied.

\section{Fully covered market and optimal zero access charge}

1. If $D_{i j}$ is monotonically increasing in $v$, there exists a threshold $x_{\theta}(\lambda, \bar{\phi})>0$ such that $\hat{\theta}=0$ when $v-c \geq \frac{1}{2}-x_{\theta}$, and $0<\hat{\theta}<1$ when $v-c<\frac{1}{2}-x_{\theta}$. 
Suppose $\hat{\theta}=0$. In order to have $\hat{\theta}=0$, it must be that $p=\underline{p}=v-c+\lambda N^{s}$. Given that $\hat{\theta}=0, D_{11}+D_{21}=D_{12}+D_{22}=\frac{1}{2}$, the CNPs' profit function is $\pi^{C N P}=$ $(f-q) N_{1}^{s}$, for any given $q \geq 0$. Thus, the optimal $f=(\bar{\phi}+q) / 2, N_{0}^{s}=\frac{1}{2}-\frac{q}{2 \phi}$, and $\bar{\phi} N_{0}^{s}=\frac{1}{\sigma_{f}^{s}}=\frac{\bar{\phi}-q}{2}$. From (26), when $\hat{\theta}=0$, the optimal $q$ satisfies $\frac{1}{2}\left(N_{0}^{s}-\frac{q}{\phi} \frac{\partial f}{\partial q}\right)=0$. Since $\left.\frac{\partial f}{\partial q}\right|_{\hat{\theta}=0}=\frac{1}{2} \frac{\left(\sigma_{f}^{s}\right)^{2}}{2\left(\sigma_{f}^{s}\right)^{2}+\frac{2 \lambda^{2}}{\phi}}$, the condition can be rewritten as

$$
\begin{aligned}
\bar{\phi} N_{0}^{s} & =q \frac{\partial f}{\partial q} \Leftrightarrow \frac{1}{\sigma_{f}^{s}}=\frac{1}{2}\left(\bar{\phi}-\frac{2}{\sigma_{f}^{s}}\right)\left(\frac{\left(\sigma_{f}^{s}\right)^{2}}{2\left(\sigma_{f}^{s}\right)^{2}+\frac{2 \lambda^{2}}{\bar{\phi}}}\right) \\
& \Leftrightarrow 1-6 N_{0}^{s}-4 \lambda^{2}\left(N_{0}^{s}\right)^{3}=0 .
\end{aligned}
$$

Let $n_{0}=N_{0}^{s}(\lambda)$ be the solution for $N_{0}^{s}$ satisfying (41). Then, from (41), $n_{0}<1 / 6$, and $q_{0}=\bar{\phi}\left(1-2 n_{0}\right)>2 \bar{\phi} / 3$. Plugging this into the condition for $\hat{\theta}=0$, we get $p_{0}=v-c+\lambda n_{0}$. To make these prices optimal, it must be that at these prices, the sign of (25) has to be negative. Since $\left.\frac{\partial f}{\partial p}\right|_{\hat{\theta}=0}=-\frac{\lambda / 2 \bar{\phi}}{\left(\sigma_{f}^{s}\right)^{2}+\frac{\lambda^{2}}{\phi}}=-\frac{\lambda \bar{\phi} n_{0}^{2}}{2\left(1+\lambda^{2} n_{0}^{2}\right)}$,

$$
\begin{aligned}
\frac{1}{2}\left(1-\frac{q_{0}}{\bar{\phi}} \frac{\partial f}{\partial p}\right)-\left(p_{0}+q_{0} N_{0}^{s}\right)<0 & \\
\Leftrightarrow p_{0}=v-c+\lambda n_{0}>\frac{1}{2} & -q_{0} n_{0}\left(1-\frac{\lambda n_{0}}{4\left(1+\lambda^{2} n_{0}^{2}\right)}\right) \\
& =\frac{1}{2}-\bar{\phi} n_{0}\left(1-2 n_{0}\right)\left(1-\frac{\lambda n_{0}}{4\left(1+\lambda^{2} n_{0}^{2}\right)}\right) .
\end{aligned}
$$

Thus, $\hat{\theta}=0$ if $v-c \geq \frac{1}{2}-x_{\theta}$, where

$$
\begin{aligned}
x_{\theta} & =\left(\lambda+q_{0}\right) n_{0}-q_{0} \frac{\lambda n_{0}^{2}}{4\left(1+\lambda^{2} n_{0}^{2}\right)} \\
& =\left(\lambda+\bar{\phi}\left(1-2 n_{0}\right)\left(1-\frac{\lambda n_{0}}{4\left(1+\lambda^{2} n_{0}^{2}\right)}\right)\right) n_{0}>0
\end{aligned}
$$

and $\frac{d x_{\theta}}{d \phi}>0$. If $D_{i j}$ is monotonically increasing in $v$, a lower $v$ increases $\hat{\theta}$. Thus, for $v-c<\frac{1}{2}-x_{\theta}, \hat{\theta}>0$.

2. If $v-c$ and $\bar{\phi}$ are small enough, the ISPs may optimally charge $q^{*}=0$.

From (26), if $\hat{\theta}=0$, it must be that $q^{*}>0$. Thus, $q^{*}=0$ can be optimal only if $\hat{\theta}>0$. From (26), for $q^{*}=0$ to be optimal, it must be that

$$
\left.\frac{\partial \pi_{i}^{I S P}}{\partial q_{i}}\right|_{q=0}=\frac{1}{2}\left(1-\hat{\theta}^{2}\right) N^{s}-p\left(\frac{\lambda \hat{\theta}}{\bar{\phi}} \frac{\partial f}{\partial q}\right) \leq 0 .
$$


Otherwise, $q^{*}>0$. From $(25)$, when $q=0$, the optimal $p$ satisfies $\frac{1}{2}\left(1-\hat{\theta}^{2}\right)=$ $p\left(1+\frac{\lambda \hat{\theta}}{\phi} \frac{\partial f}{\partial p}\right)$. Plugging this condition into (26), we get

$$
\begin{gathered}
p\left[N^{s}\left(1+\frac{\lambda \hat{\theta}}{\bar{\phi}} \frac{\partial f}{\partial p}\right)-\left(\frac{\lambda \hat{\theta}}{\bar{\phi}} \frac{\partial f}{\partial q}\right)\right] \leq 0 \\
\Leftrightarrow N^{s}\left(1+\frac{\lambda \hat{\theta}}{\bar{\phi}} \frac{\partial f}{\partial p}\right) \leq\left(\frac{\lambda \hat{\theta}}{\bar{\phi}} \frac{\partial f}{\partial q}\right) \\
\Leftrightarrow N^{s} \leq \frac{\frac{\lambda \hat{\theta}}{\phi} \frac{\partial f}{\partial q}}{\left(1+\frac{\lambda \hat{\theta}}{\phi} \frac{\partial f}{\partial p}\right)}=\frac{\frac{\hat{\theta}}{2} \frac{\lambda}{\phi}\left(\sigma_{f}^{s}+\sigma_{f}^{b}\right)^{2}}{\left(\sigma_{f}^{s}+\sigma_{f}^{b}\right)^{2}+\left(\sigma_{f}^{s}\right)^{2}+\left(1-\frac{\hat{\theta}}{2}\right) \frac{\lambda^{2}}{2 \bar{\phi}^{2} D}\left(1+\frac{\hat{\theta}^{2}}{2 D}\right)}
\end{gathered}
$$

Since $\sigma_{f}^{s}=\frac{1}{\phi N^{s}}$, we can rewrite (43) as

$$
\begin{aligned}
1 & \leq \frac{\sigma_{f}^{s} \frac{\lambda \hat{\theta}}{2}\left(\sigma_{f}^{s}+\sigma_{f}^{b}\right)^{2}}{\left(\sigma_{f}^{s}+\sigma_{f}^{b}\right)^{2}+\left(\sigma_{f}^{s}\right)^{2}+\left(1-\frac{\hat{\theta}}{2}\right) \frac{\lambda^{2}}{2 \bar{\phi}^{2} D}\left(1+\frac{\hat{\theta}^{2}}{2 D}\right)} \\
& \Leftrightarrow \sigma_{f}^{s} \frac{\lambda \hat{\theta}}{2}\left(\sigma_{f}^{s}+\sigma_{f}^{b}\right)^{2} \geq\left(\sigma_{f}^{s}+\sigma_{f}^{b}\right)^{2}+\left(\sigma_{f}^{s}\right)^{2}+\left(1-\frac{\hat{\theta}}{2}\right) \frac{\lambda^{2}}{2 \bar{\phi}^{2} D}\left(1+\frac{\hat{\theta}^{2}}{2 D}\right) \\
& \Leftrightarrow\left(\sigma_{f}^{s} \frac{\lambda \hat{\theta}}{2}-1\right)\left(\sigma_{f}^{s}+\sigma_{f}^{b}\right)^{2} \geq\left(\sigma_{f}^{s}\right)^{2}+\left(1-\frac{\hat{\theta}}{2}\right)\left(\sigma_{f}^{b}\right)^{2}+\left(1-\frac{\hat{\theta}}{2}\right) \frac{\lambda^{2}}{2 \bar{\phi}^{2} D}
\end{aligned}
$$

This condition is possible only if $\hat{\theta}$ is large enough, which occurs for a small $v-c$. Also, it requires a large enough $\sigma_{f}^{s}$. This is possible if $\bar{\phi}$ is small. Thus, for small $v-c$ and $\bar{\phi}$, it is possible that the ISPs optimally set the access charges at zero.

\section{Proof of Proposition 3}

Let $\gamma_{p}=\left(\frac{\partial N}{\partial p}\right) \frac{p}{N}=\left(\frac{-1}{\phi} \frac{\partial f}{\partial p}\right) \frac{p}{N}>0$ and $\delta=\frac{p}{a N^{s}}>0$. From (29), when $\hat{\theta}>0$, the optimal $p_{a}$ satisfies

$$
\begin{aligned}
\Psi & =\sum D_{i j}\left(1-\frac{a}{\bar{\phi}} \frac{\partial f}{\partial p}\right)+\frac{\partial \sum D_{i j}}{\partial p}\left(p_{a}+a N^{s}\right)=0 \\
& \Leftrightarrow p_{a}\left(1-\frac{a}{\bar{\phi}} \frac{\partial f}{\partial p}\right)=\varepsilon_{p}\left(p_{a}+a N^{s}\right) \\
& \Leftrightarrow a N^{s}\left(\gamma_{p}-\varepsilon_{p}\right)=\left(\varepsilon_{p}-1\right) p_{a} \\
& \Leftrightarrow \gamma_{p}=\varepsilon_{p}+\left(\varepsilon_{p}-1\right) \delta
\end{aligned}
$$

Equation (46) implies that $\gamma_{p}>\varepsilon_{p}$ if and only if $\varepsilon_{p}>1$. 
Similarly, let $\varepsilon_{a}=-a\left(\frac{\partial \sum D_{i j}}{\partial a}\right) / \sum D_{i j}$ and $\gamma_{a}=-\left(\frac{\partial N}{\partial a}\right) \frac{a}{N}$. Then,

$$
\begin{aligned}
\varepsilon_{a} & =\left(\frac{\lambda \hat{\theta}}{\bar{\phi}} \frac{\partial f}{\partial a}\right) \frac{a}{2 D}=\sigma_{f}^{b}\left(a \frac{\partial f}{\partial a}\right), \text { and } \\
\gamma_{a} & =\left(\frac{1}{\bar{\phi}} \frac{\partial f}{\partial a}\right) \frac{a}{N}=\sigma_{f}^{s}\left(a \frac{\partial f}{\partial a}\right) .
\end{aligned}
$$

From (26), at the optimal $q^{*}, N-q\left(\frac{\partial N}{\partial q}\right) \geq 0$. Thus, $\gamma_{q}=-q\left(\frac{\partial N}{\partial q}\right) / N=\left(\frac{1}{\phi} \frac{\partial f}{\partial q}\right) \frac{q}{N} \leq 1$. Since for $a<q^{*}, N-a\left(\frac{\partial N}{\partial a}\right)>0$ from (26), $\gamma_{a}<1$. From (18), $\left(p+a N^{s}\right)=$ $\frac{p}{\varepsilon_{p}}\left(1-\frac{a}{\phi} \frac{\partial f}{\partial p}\right)=\frac{a N}{\varepsilon_{p}}\left(\delta+\gamma_{p}\right)$. Moreover, from (19), at $a=q^{*}$

$$
\left(1-\gamma_{a}\right)-\varepsilon_{a}(1+\delta)=0
$$

By the Implicit Function Theorem, $\frac{d p}{d a}=\frac{1}{-S O C_{p_{a}}}\left(\frac{\partial \Psi}{\partial a}\right)$, where $S O C_{p_{a}}<0$. Hence, the sign of $\frac{d p}{d a}$ depends on the sign of $\partial \Psi / \partial a$ :

$$
\begin{aligned}
\frac{\partial \Psi}{\partial a}= & \frac{\partial \sum D_{i j}}{d a}\left(1-\frac{a}{\bar{\phi}} \frac{\partial f}{\partial p}\right)+\sum D_{i j}\left(-\frac{1}{\bar{\phi}} \frac{\partial f}{\partial p}\right) \\
& +\sum D_{i j}\left(-\frac{a}{\bar{\phi}} \frac{\partial^{2} f}{\partial p \partial a}\right)+\frac{\partial \sum D_{i j}}{\partial p_{i}}\left[N^{s}+a\left(\frac{\partial N}{\partial a}\right)\right]+\frac{\partial^{2} \sum D_{i j}}{\partial p_{i} \partial a}\left(p_{a}+a N^{s}\right)
\end{aligned}
$$

From (22) and (38), $\frac{\partial^{2} f}{\partial p \partial a}=0$. Then, collecting terms we get,

$$
\begin{aligned}
\frac{\partial \Psi}{\partial a}= & \sum D_{i j}\left[\frac{\partial \sum D_{i j} / d a}{\sum D_{i j}}-\varepsilon_{a} \frac{\partial N^{s}}{\partial p}+\left(\frac{\partial N^{s}}{\partial p}\right)-\varepsilon_{p}\left(\frac{N^{s}+a\left(\frac{\partial N^{s}}{\partial a}\right)}{p}\right)\right] \\
& +\left(-\frac{\lambda}{\bar{\phi}} \frac{\partial f}{\partial a}\right)\left(\frac{\lambda}{\bar{\phi}} \frac{\partial f}{\partial p}\right) \frac{a N}{\varepsilon_{p}}\left(\delta+\gamma_{p}\right) \\
= & \frac{\sum D_{i j} N^{s}}{p}\left[\gamma_{p}\left(1-\varepsilon_{a}\right)-\varepsilon_{p}\left(1-\gamma_{a}\right)-\delta \varepsilon_{a}\right]+\frac{\lambda^{2} N^{3}}{p} \gamma_{p} \gamma_{a} \frac{\left(\delta+\gamma_{p}\right)}{\varepsilon_{p}}
\end{aligned}
$$

Plugging the conditions for $\gamma_{p}, \varepsilon_{p}, \gamma_{a}$, and $\varepsilon_{a}$ from (47) and (48) and rearranging terms, we get

$$
\frac{\partial \Psi}{\partial a}=\frac{\sum D_{i j} N^{s}}{p}\left(\gamma_{p}-2 \varepsilon_{p}\left(1-\gamma_{a}\right)+\frac{\lambda^{2} N^{2}}{2 D} \frac{\left(\gamma_{p}-1\right)}{\left(\varepsilon_{p}-1\right)} \gamma_{p} \gamma_{a}\right)
$$

where $\frac{\left(\gamma_{p}-1\right)}{\left(\varepsilon_{p}-1\right)}=\frac{\left(1-\gamma_{p}\right)}{\left(1-\varepsilon_{p}\right)}>0$. Thus, $\frac{d p}{d a}>0$ if and only if

$$
\gamma_{p}\left(1+\kappa \gamma_{a} \frac{\left(\gamma_{p}-1\right)}{\left(\varepsilon_{p}-1\right)}\right)>2 \varepsilon_{p}\left(1-\gamma_{a}\right)
$$


where $\kappa=\frac{\lambda N^{s 2}}{2 D}$. This condition is more likely to hold if $\gamma_{p}$ and $\gamma_{a}$ are large for a given $\varepsilon_{p}$.

\section{Proof of Proposition 4}

From (27), for $a=q^{*}, p=p^{*}$, and the optimal advertising fee $f^{*}$ satisfies 1 $\left(f^{*}-a\right)\left[\sigma_{f}^{s}\left(f^{*}\right)+\sigma_{f}^{b}\left(p^{*}\right)\right]=0$. When $a<q^{*}, p=p_{a}$, and the optimal $f_{a}$ satisfies $1-\left(f_{a}-a\right)\left[\sigma_{f a}^{s}\left(f_{a}\right)+\sigma_{f a}^{b}\left(p_{a}\right)\right]=0$. Evaluating the equation for $f^{*}$ at $f_{a}$ and $p_{a}$, we get $-\left(a-q^{*}\right)\left[\sigma_{f a}^{s}+\sigma_{f a}^{b}\right]>0$, which implies that $f_{a}<f^{*}$.

\section{Proof of Proposition 5}

There are 2 cases to consider.

Case 1. $\frac{d p}{d a}>0$. In this case, $\frac{d \hat{\theta}}{d a}=\frac{d p}{d a}+\frac{\lambda}{\phi} \frac{d f}{d a}>0$ given that $\frac{d f}{d a}>0$. Thus, access regulation induces greater consumer demand for the Internet. In this case, $\frac{d W}{d a}<0$ from $(51)$ since $\left[A-\left(1-\hat{\theta}^{2}\right)\right]=(1-\hat{\theta})^{2}+2 \hat{\theta}\left(\frac{\bar{\phi}^{2}-f^{2}}{2 \bar{\phi}}+p\right)>0$. Therefore, a lower $a$ improves total welfare unambiguously.

Case 2. $\frac{d p}{d a}<0$. In this case, consumer demand for the Internet may or may not increase given that $\frac{d \hat{\theta}}{d a}=\frac{d p}{d a}+\frac{\lambda}{\phi} \frac{d f}{d a}=\frac{d p}{d a}\left(1+\frac{\lambda}{\phi} \frac{\partial f}{\partial p}\right)+\frac{\lambda}{\phi} \frac{\partial f}{\partial a} \gtrless 0$. However, if it does, it means that $\frac{d \hat{\theta}}{d a}>0 \Leftrightarrow \frac{\lambda}{\phi} \frac{d f}{d a}>\left|\frac{d p}{d a}\right|$. Therefore, from (31), $\frac{d W}{d a}<0$ because $\left(A+\left(1-\hat{\theta}^{2}\right) \frac{f}{\lambda}\right)>A-\left(1-\hat{\theta}^{2}\right)>0$ and $\frac{\lambda}{\phi} \frac{d f}{d a}>\left|\frac{d p}{d a}\right|$. Therefore, a lower $a$ improves welfare.

In summary, access regulation improves total welfare if it results in higher consumer demand for the Internet.

\section{Proof of Proposition 6}

Since $\frac{d \hat{\theta}}{d a}=\frac{d p}{d a}+\frac{\lambda}{\phi} \frac{d f}{d a}$, and $\frac{d f}{d a}=\frac{\partial f}{\partial a}+\left(\frac{\partial f}{\partial p}\right) \frac{d p}{d a}$

$$
\begin{gathered}
\frac{d W}{d a}=A\left(-\frac{d p}{d a}-\frac{\lambda}{\bar{\phi}} \frac{d f}{d a}\right)+\left(1-\hat{\theta}^{2}\right)\left(\frac{d p}{d a}-\frac{f}{\bar{\phi}} \frac{d f}{d a}\right) \\
=-\left(A+\left(1-\hat{\theta}^{2}\right) \frac{f}{\lambda}\right)\left(\frac{\lambda}{\bar{\phi}} \frac{d f}{d a}\right)-\left[A-\left(1-\hat{\theta}^{2}\right)\right] \frac{d p}{d a} \\
=-\left(A+\left(1-\hat{\theta}^{2}\right) \frac{f}{\lambda}\right)\left(\frac{\lambda}{\bar{\phi}} \frac{\partial f}{\partial a}+\frac{\lambda}{\bar{\phi}}\left(\frac{\partial f}{\partial p}\right) \frac{d p}{d a}\right)-\frac{d p}{d a}\left[A-\left(1-\hat{\theta}^{2}\right)\right] \\
=-\left(A+\left(1-\hat{\theta}^{2}\right) \frac{f}{\lambda}\right) \frac{\lambda}{\bar{\phi}}\left(\frac{\partial f}{\partial a}\right) \\
-\frac{d p}{d a} \underbrace{\left[A\left(1+\left(\frac{\partial f}{\partial p}\right) \frac{\lambda}{\bar{\phi}}\right)-\left(1-\hat{\theta}^{2}\right)\left(1-\left(\frac{\partial f}{\partial p}\right) \frac{f}{\bar{\phi}}\right)\right]}_{B}
\end{gathered}
$$


Given that $\frac{d f}{d a}>0, \frac{d W}{d a}>0$ is possible only if $\frac{d p}{d a}<0$ and $\frac{d p}{d a} B<0$. Thus, it must be that $B=\left[A-\left(1-\hat{\theta}^{2}\right)+\left(\frac{\partial f}{\partial p}\right) \frac{\lambda}{\phi}\left(A+\left(1-\hat{\theta}^{2}\right) \frac{f}{\lambda}\right)\right]>0 \Leftrightarrow\left|\left(\frac{\partial f}{\partial p}\right) \frac{\lambda}{\phi}\right|<\frac{A-\left(1-\hat{\theta}^{2}\right)}{\left(A+\left(1-\hat{\theta}^{2}\right) \frac{f}{\lambda}\right)}$.

Since $\frac{d p}{d a}<0$ is more likely to hold for a smaller $\left|\frac{\partial f}{\partial p}\right|$, the condition $\frac{d p}{d a} B<0$ can be easily satisfied for a small $\left|\frac{\partial f}{\partial p}\right|$. When $\frac{d p}{d a} B<0$, from (53), $\frac{d W}{d a}>0$ only if $\left|\frac{d p}{d a}\right|>$ $\left(A+\left(1-\hat{\theta}^{2}\right) \frac{f}{\lambda}\right) \frac{\lambda}{\phi}\left(\frac{\partial f}{\partial a}\right) / B \Leftrightarrow \frac{X \frac{\lambda}{\phi}\left(\frac{\partial f}{\partial a}\right)}{\left[A-\left(1-\hat{\theta}^{2}\right)+X\left(\frac{\partial f}{\partial p}\right) \frac{\lambda}{\phi}\right]}$, where $X=\left(A+\left(1-\hat{\theta}^{2}\right) \frac{f}{\lambda}\right)$. This condition holds for small $\left(\frac{\partial f}{\partial p}\right)$ and $\left(\frac{\partial f}{\partial a}\right)$.

\section{Proof of Corollary 2}

$\frac{d W}{d a}>0$ occurs when $\frac{d p}{d a}<0$ and $\left|\frac{d p}{d a}\right|$ is large enough. From (49), $\frac{d p}{d a}$ becomes increasingly negative for a high $\varepsilon_{p}$ and low $\gamma_{a}$ and low $\gamma_{p}$.

\section{Proof of Corollary 3}

1. From $(27)$, for $a=q^{*}$, the optimal advertising fees satisfy $1-\left(f^{*}-a\right)\left[\sigma_{f}^{s}+\sigma_{f}^{b}\right]=$ 0 . When $a=0$, the optimal $f_{N}$ satisfies $1-\left(f_{N}\right)\left[\sigma_{f N}^{s}+\sigma_{f N}^{b}\right]=0$. Evaluating the equation for $f^{*}$ at $f_{N}$, we get $a\left[\sigma_{f N}^{s}+\sigma_{f N}^{b}\right]>0$, which implies that $f_{N}<$ $f^{*}$.

2. From (29), at $a=q^{*}$, the optimal $p^{*}$ satisfies

$$
\Psi_{1}\left(p^{*}\right)=\sum D_{i j}\left(1-\frac{q^{*}}{\bar{\phi}} \frac{\partial f}{\partial p}\right)+\frac{\partial \sum D_{i j}}{d p}\left(p^{*}+q^{*} N^{s}\right)=0 .
$$

On the other hand, when $a=0$, the optimal $p_{N}$ satisfies

$$
\begin{aligned}
\Psi_{2}\left(p_{N}\right) & =\sum D_{i j}+\frac{\partial \sum D_{i j}}{d p} p_{a}=0 \\
& \Leftrightarrow \varepsilon_{p}\left(p_{N}\right)=1 .
\end{aligned}
$$

Then, evaluating $\Psi_{1}$ at $p_{N}$, we get

$$
\begin{aligned}
\Psi_{1}\left(p_{N}\right) & =\sum D_{i j}\left(-\frac{q^{*}}{\bar{\phi}} \frac{\partial f}{\partial p}\right)+\frac{\partial \sum D_{i j}}{d p} q^{*} N^{s} \\
& \Rightarrow \operatorname{sign} \Psi_{1}\left(p_{N}\right)=\operatorname{sign}\left(\gamma_{p_{N}}-1\right) .
\end{aligned}
$$

Thus, if $\gamma_{p_{N}}>1, \Psi_{1}\left(p_{N}\right)>0$, which implies that $p_{N}<p^{*}$. Otherwise, $p_{N}>p^{*}$. If $p_{N}<p^{*}$, since $f_{N}<f^{*}, \Delta \hat{\theta}=\hat{\theta}_{N}-\hat{\theta}=p_{N}-p^{*}-\lambda\left(N_{N}-N^{s}\right)<0$, and thus, consumer welfare increases and the profits for CPs and CNPs increase. As a result, the total welfare improves. 
3. Welfare decreases only if $p_{N}>p^{*}$. If $p_{N}>p^{*}$, given that $f_{N}<f^{*}, \Delta \hat{\theta}=\hat{\theta}_{N}-$ $\hat{\theta}=p_{N}-p^{*}-\lambda\left(N_{N}-N^{s}\right) \gtrless 0$. If $\Delta \hat{\theta}>0$, consumer welfare decreases. The total welfare decreases if $\Delta p$ is large enough, which holds for a small $\gamma_{p_{N}}$.

\section{References}

[1] Armstrong, M. (2006). "Competition in two-sided markets." RAND Journal of Economics, 37, pp. 668-691.

[2] Caillaud, B. and B. Jullien (2003). "Chicken \& egg: Competition among intermediation service providers" RAND Journal of Economics, 34, pp. 309-328.

[3] Cheng, H. K., S. Bandyopadhyay, and H. Guo (2011). "The debate on Net Neutrality: A policy perspective." Information Systems Research, 22, pp. 1-27.

[4] Choi, J. P. and B.C., Kim (2010). "Net Neutrality and investment incentives." RAND Journal of Economics, 41, pp. 446-471.

[5] Economides, N. and J. Tåg (2012). "Net Neutrality on the Internet: A two-sided market analysis. Forthcoming. Information Economics and Policy.

[6] Economides, N. and B.E. Hermalin (2010). "The Economics of Net Neutrality." Forthcoming. RAND Journal of Economics.

[7] Hermalin, B. E. and M. L. Katz (2007). "The Economics of Product-Line Restrictions With an Application to the Network Neutrality Debate." Information Economics and Policy, 19, pp. 215-248.

[8] Krämer, J. and L. Wiewiorra (2010). "Network neutrality and congestionsensitive content providers: Implications for service innovation, broadband investment and regulation.” Working Paper, Karlsruhe Institute of Technology.

[9] Lee, R. S. and T.Wu (2009). "Subsidizing creativity through network design: Zero-pricing and NN." Journal of Economic Perspectives. 23, pp. 61-76.

[10] Musacchio, J., G. Schwartz, and J. Walrand (2009). "A two-sided market analysis of provider investment incentives with an application to the net-neutrality issue." Review of Network Economics. 8, pp. 22-39.

[11] Rochet, J.-C. and J. Tirole (2003). "Platform competition in two-sided markets." Journal of the European Economic Association, 1, pp. 990-1029. 
[12] Rochet, J.-C. and J. Tirole (2006). "Two-sided markets-a progress report," RAND Journal of Economics, 37(3), pp. 645-667.

[13] Schuett, F. (2010). "Network neutrality: A survey of the economic literature." Review of Network Economics. 9, pp. 1-13.

[14] Weisman, D. and R. Kulick (2010). "Price Discrimination, Two-Sided Markets and Net Neutrality Regulation," Tulane Journal of Technology and Intellectual Property, Vol. 13, Fall 2010, pp. 81-102.

[15] Weyl, G. (2008). "Double Marginalization in Two-Sided Markets," mimeo.

[16] Weyl, G. (2010). "A Price Theory of Multi-sided Platforms," American Economic Review, Vol. 100, pp.1642-1672.

\section{Technical Appendix}

In this Appendix, we describe when the market is fully covered as a result of regulation. First, we show that under access regulation, if $D_{i j}$ is monotonically increasing in $v$, there exists a threshold $x_{a}(\lambda, \bar{\phi})>0$ such that $\hat{\theta}_{a}=0$ when $v-c \geq \frac{1}{2}-x_{a}$, and $0<\hat{\theta}_{a}<1$ when $v-c<\frac{1}{2}-x_{a}$. We find that the threshold for full market coverage is lower under regulation than without regulation, i.e., $x_{a}>x_{\theta}$. Thus, we have three cases: (i) $v-c \geq \frac{1}{2}-x_{\theta}$, (ii) $\frac{1}{2}-x_{a} \leq v-c<\frac{1}{2}-x_{\theta}$, or (iii) $v-c<\frac{1}{2}-x_{a}$. The main body of this paper focuses on case (iii) where the market is not fully covered regardless of regulation. Here, we provide welfare implication of access regulation for the cases (i) and (ii).

\subsection{Fully covered market under access regulation}

As before regulation, we have two types of equilibria: when $\hat{\theta}_{a}=0$, and when $0<$ $\hat{\theta}_{a}<1$. The only difference is that the parameter ranges for the two cases now depend on the level of regulated access charges $a$. If $D_{i j}$ is monotonically increasing in $v$, there exists a threshold $x_{a}(\lambda, \bar{\phi})>0$ such that $\hat{\theta}_{a}=0$ when $v-c \geq \frac{1}{2}-x_{a}$, and $0<\hat{\theta}_{a}<1$ when $v-c<\frac{1}{2}-x_{a}$.

By construction, $\hat{\theta}_{a}=0$, only if $p_{a}=\underline{p_{a}}=v-c+\lambda N_{a}^{s}$. From $(27)$, when $\hat{\theta}_{a}=0$, $\sigma_{f}^{b}=0$, and thus, $f_{a}=\frac{a+\bar{\phi}}{2}$. Then, we get $n_{a 0}=N_{a}^{s}(a)=\frac{1}{2}-\frac{a}{2 \phi}$. Evaluating (29) at $p_{a}=\underline{p_{a}}$, we get

$$
\left.\frac{\partial \pi_{i a}^{I S P}}{\partial p_{i}}\right|_{\underline{p_{a}}}=\frac{1}{2}-(a+\lambda) n_{a 0}+\frac{a}{4} \frac{\lambda n_{a 0}^{2}}{\left(1+\lambda^{2} n_{a 0}^{2}\right)}-(v-c) .
$$


Let $x_{a}=(a+\lambda) n_{a 0}-\left(\frac{a \lambda n_{a 0}^{2}}{4\left(1+\lambda^{2} n_{a 0}^{2}\right)}\right)$. If $v-c \geq \frac{1}{2}-x_{a}$, then $\hat{\theta}_{a}=0$ is optimal, while if $v-c<\frac{1}{2}-x_{a}$, then $\hat{\theta}_{a}>0$ is optimal.

Since $a<q^{*}$, and $\frac{d f}{d a}>0$ from Proposition $4, N_{a}^{s}>N^{s}$, thus $\underline{p_{a}}>\underline{p}$. Since $\underline{p_{a}}>\underline{p}$, (55) evaluated at $\underline{p}$ must be greater than (55) evaluated at $\underline{p_{a}}$. That is,

$$
\begin{aligned}
\left.\frac{\partial \pi_{i a}^{I S P}}{\partial p_{i}}\right|_{\underline{p_{a}}} & =\frac{1}{2} \underbrace{-(a+\lambda) n_{a 0}+\frac{a}{4} \frac{\lambda n_{a 0}^{2}}{\left(1+\lambda^{2} n_{a 0}^{2}\right)}}_{-x_{a}}-(v-c) \\
& <\frac{1}{2} \underbrace{-\left(q_{0}+\lambda\right) n_{0}+\frac{q_{0}}{4} \frac{\lambda n_{0}^{2}}{\left(1+\lambda^{2} n_{0}^{2}\right)}}_{-x_{\theta}}-(v-c)=\left.\frac{\partial \pi_{i a}^{I S P}}{\partial p_{i}}\right|_{\underline{p}} .
\end{aligned}
$$

Therefore, $x_{a}>x_{\theta}$.

7.2 When $v-c \geq \frac{1}{2}-x_{\theta}$

In this case, access regulation improves total welfare. In this parameter range, consumer demand for the Internet is fully covered whether or not there is access regulation. CPs' profits improve unambiguously since the fees are lower. Since $f_{a}=(\bar{\phi}+a) / 2<\left(\bar{\phi}+q_{0}\right) / 2=f_{0}$, the total CPs' surplus is

$$
\int_{f_{a}}^{\bar{\phi}} \frac{\left(\phi-f_{a}\right)}{\bar{\phi}} d \phi-\int_{f_{0}}^{\bar{\phi}} \frac{\left(\phi-f_{0}\right)}{\bar{\phi}} d \phi=\left(f_{0}-f_{a}\right)\left(1-\frac{\left(f_{0}+f_{a}\right)}{2 \bar{\phi}}\right)>0 .
$$

There are more CPs and each of them enjoys higher profits than before. Consumer $i$ welfare $u=\theta-p+\left(\nu-c+\lambda N^{s}\right)=\theta$ is unaffected since there is no change in the participating consumers and the increase in network externality is offset by an increase in the Internet connection price they pay. CNPs' profits stay the same since the profits are

$$
\begin{aligned}
& \pi_{q}^{C N P}=\frac{1}{2}\left(f_{0}-q_{0}\right) N_{0}^{s}=\frac{1}{2} \frac{1}{\bar{\phi} N_{0}^{s}} N_{0}^{s}=\frac{1}{2} \frac{1}{\bar{\phi}} \text { and } \\
& \pi_{a}^{C N P}=\frac{1}{2}\left(f_{a}-q_{a}\right) N_{a}^{s}=\frac{1}{2} \frac{1}{\bar{\phi} N_{a}^{s}} N_{a}^{s}=\frac{1}{2} \frac{1}{\bar{\phi}}
\end{aligned}
$$

before and after regulation, respectively.

ISPs' profits may not decrease if $a$ is not too low. Since $p_{a}=v-c+\lambda n_{a}>$ $v-c+\lambda n_{0}=p_{0}$, ISPs' profits from consumer Internet subscription increase as a result of a higher consumer price. Access revenues increase as well if the regulated 
access $a$ is not much lower than $q$.

$$
\begin{aligned}
\pi_{a}^{I S P}-\pi_{q}^{I S P} & =\frac{1}{2}\left(p_{a}+a n_{a}\right)-\frac{1}{2}\left(p_{0}+q_{0} n_{0}\right) \\
& =\frac{1}{2}\left(f_{0}-f_{a}\right)\left(\frac{\lambda}{2 \bar{\phi}}+\frac{2\left(f_{0}+f_{a}\right)-3 \bar{\phi}}{2 \bar{\phi}}\right) .
\end{aligned}
$$

Since $f_{0}=\bar{\phi}\left(1-n_{0}\right)>5 \bar{\phi} / 6$, if $\bar{\phi} / 2<a<q_{0}, f_{a}>3 \bar{\phi} / 4$, and $2\left(f_{0}+f_{a}\right)-3 \bar{\phi}>0$, and thus, ISPs' profits also increase as a result of access regulation. Even if access revenues decrease as a result of low $a$, ISPs' profits increase as a result of regulation if $\lambda>$ $3 \bar{\phi}-2\left(f_{0}+f_{a}\right)$. This is because access regulation induces greater participation of CPs, which increases transaction volume and thus, access revenues for the ISPs increase. While the level of access charges at $a$ that permits higher profits is available for unregulated ISPs, ISPs are unable to commit to it due to the competition within the ISPs. This shows that there is inefficiency in the market, and that access regulation can improve welfare by removing the inefficiency.

Even if ISPs' profits decrease, the total welfare improves as a result of regulation in this region.

$$
\Delta W=\left(f_{0}-f_{a}\right)\left(\frac{\lambda}{2 \bar{\phi}}+\frac{\left(f_{0}+f_{a}\right)-\bar{\phi}}{2 \bar{\phi}}\right)>0
$$

since $f_{0}>5 \bar{\phi} / 6, f_{a}>\bar{\phi} / 2$ for any $a \geq 0$, and $\left(f_{0}+f_{a}\right)>\bar{\phi}$.

\subsection{When $\frac{1}{2}-x_{a} \leq v-c<\frac{1}{2}-x_{\theta}$}

In this case, access regulation induces a fully covered market while without regulation, the market demand for the Internet is not fully covered. Thus, consumer welfare is higher under regulation. Since $\hat{\theta}_{a}=0, p_{a}=v-c+\lambda n_{a}$ and without regulation, $\hat{\theta}>0$, and thus, $p^{*}>v-c+\lambda N^{s}$. The equilibrium Internet price may or may not be lower under regulation. However, as $\Delta \hat{\theta}=\hat{\theta}_{a}-\hat{\theta}=\Delta p-\lambda \Delta N^{s}<0$, even if the price increases, the increase is not as large as the increase in network externality in this region.

Since $f_{a}<f^{*}, n_{a}>N^{s}$. Since consumer demand is higher under regulation and CPs' profits improve as a result of regulation, the overall welfare effect is straightforward from Proposition 5. 